\title{
Transcriptome and structure analysis in root of Casuarina equisetifolia under $\mathrm{NaCl}$ treatment
}

\author{
Yujiao Wang Equal first author, 1, 2 , Jin Zhang Equal frrst author, 3 , Zhenfei Qiu ${ }^{1}$, Bingshan Zeng ${ }^{1}$, Yong Zhang ${ }^{1}$, Xiaoping Wang ${ }^{1}$, \\ Jun Chen ${ }^{2}$, Chonglu Zhong ${ }^{1}$, Rufang Deng ${ }^{4}$, Chunjie Fan ${ }^{\text {Corresp. } 1,2}$ \\ ${ }^{1}$ Key Laboratory of State Forestry and Grassland Administration on Tropical Forestry Research, Research Institute of Tropical Forestry, Chinese Academy \\ of Forestry, Guangzhou, China \\ 2 State Key Laboratory of Tree Genetics and Breeding, Chinese Academy of Forestry, Beijing, China \\ 3 State Key Laboratory of Subtropical Silviculture, School of Forestry and Biotechnology, Zhejiang Agriculture and Forestry University, Hangzhou, China \\ 4 South China Botanical Garden, Chinese Academy of Sciences, Guangzhou, China \\ Corresponding Author: Chunjie Fan \\ Email address: fanchunjie@caf.ac.cn
}

Background: High soil salinity seriously affects plant growth and development. Excessive salt ions mainly cause damage by inducing osmotic stress, ion toxicity, and oxidation stress. Casuarina equisetifolia is a highly salt-tolerant plant, commonly grown as wind belts in coastal areas with sandy soils. However, little is known about its physiology and the molecular mechanism of its response to salt stress.

Results: Eight-week-old $C$. equisetifolia seedlings grown from rooted cuttings were exposed to salt stress for varying durations $(0,1,6,24$, and $168 \mathrm{~h}$ under $200 \mathrm{mM} \mathrm{NaCl})$ and their ion contents, cellular structure, and transcriptomes were analyzed. Potassium concentration decreased slowly between $1 \mathrm{~h}$ and $24 \mathrm{~h}$ after initiation of salt treatment, while the content of potassium was significantly lower after $168 \mathrm{~h}$ of salt treatment. Root epidermal cells were shed and a more compact layer of cells formed as the treatment duration increased. Salt stress led to deformation of cells and damage to mitochondria in the epidermis and endodermis, whereas stele cells suffered less damage. Transcriptome analysis identified 10,378 differentially expressed genes (DEGs), with more genes showing differential expression after $24 \mathrm{~h}$ and $168 \mathrm{~h}$ of exposure than after shorter durations of exposure to salinity. Signal transduction and ion transport genes such as HKT and CHX were enriched among DEGs in the early stages ( $1 \mathrm{~h}$ or $6 \mathrm{~h}$ ) of salt stress, while expression of genes involved in programmed cell death was significantly upregulated at 168 $\mathrm{h}$, corresponding to changes in ion contents and cell structure of roots. Oxidative stress and detoxification genes were also expressed differentially and were enriched among DEGs at different stages.

Conclusions: These results not only elucidate the mechanism and the molecular pathway governing salt tolerance, but also serve as a basis for identifying gene function related to salt stress in $C$. equisetifolia. 


\section{Transcriptome and structure analysis in root of Casuarina}

\section{2 equisetifolia under $\mathrm{NaCl}$ treatment}

\section{Yujiao Wang ${ }^{2 *}$, Jin Zhang ${ }^{3}$, Zhenfei Qiu ${ }^{2}$, Bingshan Zeng², Yong Zhang ${ }^{2}$, Xiaoping}

4 Wang $^{2}$, Jun Chen ${ }^{1}$, Chonglu Zhong ${ }^{2}$, Rufang Deng ${ }^{4}$, Chunjie Fan ${ }^{12}$

$5{ }^{1}$ State Key Laboratory of Tree Genetics and Breeding, Chinese Academy of Forestry, Beijing

6 100091, China

$7 \quad 2$ Key Laboratory of State Forestry and Grassland Administration on Tropical Forestry Research,

8 Research Institute of Tropical Forestry, Chinese Academy of Forestry, Guangzhou, 510520,

9 China

$10{ }^{3}$ State Key Laboratory of Subtropical Silviculture, School of Forestry and Biotechnology,

11 Zhejiang A\&F University, Hangzhou, Zhejiang 311300, China

$12{ }^{4}$ South China Botanical Garden, Chinese Academy of Sciences, Guangzhou 510650, China

14 Corresponding author:

15 Chunjie Fan:

16 No. 682, Guangshan $1^{\text {st }}$ Road, Guangzhou, Guangdong, 510520, China

Email address: fanchunjie@,caf.ac.cn

*Yujiao Wang and Jin Zhang contributed equally to this work. 
23 Abstract

24 Background:

High soil salinity seriously affects plant growth and development. Excessive salt ions mainly cause damage by inducing osmotic stress, ion toxicity, and oxidation stress. Casuarina equisetifolia is a highly salt-tolerant plant, commonly grown as wind belts in coastal areas with sandy soils. However, little is known about its physiology and the molecular mechanism of its response to salt stress.

Results:

Eight-week-old C. equisetifolia seedlings grown from rooted cuttings were exposed to salt stress for varying durations $(0,1,6,24$, and $168 \mathrm{~h}$ under $200 \mathrm{mM} \mathrm{NaCl})$ and their ion contents, cellular structure, and transcriptomes were analyzed. Potassium concentration decreased slowly between $1 \mathrm{~h}$ and $24 \mathrm{~h}$ after initiation of salt treatment, while the content of potassium was significantly lower after $168 \mathrm{~h}$ of salt treatment. Root epidermal cells were shed and a more compact layer of cells formed as the treatment duration increased. Salt stress led to deformation of cells and damage to mitochondria in the epidermis and endodermis, whereas stele cells suffered less damage. Transcriptome analysis identified 10,378 differentially expressed genes (DEGs), with more genes showing differential expression after $24 \mathrm{~h}$ and $168 \mathrm{~h}$ of exposure than after shorter durations of exposure to salinity. Signal transduction and ion transport genes such as $H K T$ and $C H X$ were enriched among DEGs in the early stages ( $1 \mathrm{~h}$ or $6 \mathrm{~h}$ ) of salt stress, while expression of genes involved in programmed cell death was significantly upregulated at $168 \mathrm{~h}$, corresponding to changes in ion contents and cell structure of roots. Oxidative stress and detoxification genes were also expressed differentially and were enriched among DEGs at different stages.

\section{Conclusions:}

These results not only elucidate the mechanism and the molecular pathway governing salt tolerance, but also serve as a basis for identifying gene function related to salt stress in $C$. equisetifolia.

Keywords: Salt stress, Differentially expressed genes, Epidermal cells, Ion content, Programmed cell death 


\section{Introduction}

Salinity resulting mainly from sodium chloride $(\mathrm{NaCl})$ is one of the most severe environmental stresses on plants. Salt stress damages root structure, hindering the absorption of nutrients by plant roots, which affects normal growth and development. The perception of $\mathrm{Na}^{+}$in roots is a rapid process, leading to osmotic stress and a rapid increase in the cytoplasmic $\mathrm{Ca}^{2+}$ concentration of roots (Choi et al., 2014; Deinlein et al., 2014). Kinases associated with $\mathrm{Ca}^{2+}$ signaling such as calcium dependent protein kinases (CDPKs), calcineurin B-like proteins (CBLs), and protein kinases (CIPKs) further regulate downstream protein activity and gene transcription (Boudsocq \& Sheen, 2013; Das \& Pandey, 2010; Weinl \& Kudla, 2009). Small amounts of reactive oxygen species (ROS) are used as signaling molecules in response to salt stresses; however, high concentrations cause oxidative damage (Laloi \& Danon, 2004; Suzuki et al., 2012; Gill \& Tuteja, 2010). After sensing salt stress signals, plants respond to stress by regulating $\mathrm{Na}^{+}$transport and maintaining ion balance to reduce damage (Morton et al., 2019; van Zelm et al., 2020). OsHKT1 transports $\mathrm{Na}^{+}$into root cells in rice, compensating for $\mathrm{K}^{+}$deficiency (Horie et al., 2001). Overexpression of StNHX1, OsHAK5, and HbHAK1 makes plants highly tolerant to salt stress (Chen et al., 2014; Zhang et al., 2020; Horie et al 2011). The SOS (salt overly sensitive) signaling pathway is a well-studied pathway closely related to plant salt tolerance (Qiu et al., 2002). SOS2 and SOS3 act together to regulate the $\mathrm{Na}^{+} / \mathrm{H}^{+}$anti-transporter SOS1 (Halfter et al., 2000), which occurs mainly in roots and maintains intracellular and extracellular ion balance by transporting $\mathrm{Na}^{+}$to the extracellular space, relieving ionic toxicity (Ishitani et al., 2000). Phytohormones are crucial endogenous chemical signals coordinating plant growth and environmental challenges (Park et al., 2016). For example, abscisic acid (ABA) and jasmonic acid (JA) play important roles in helping plants to cope with salt stress by growth repression or sensing signals (Yu et al., 2020; Chen et al., 2016; Geng et al., 2013). Furthermore, gene ontology (GO) terms for plant hormone pathways in the selected gene modules of Populus are enriched under salt stress (Liu et al., 2019). These results suggest that salt tolerance is a complex trait that involves a coordinated response to osmotic and ionic stresses and their subsequent secondary stresses.

Casuarina, an angiosperm plant widely grown in the tropics and subtropics, is the main tree genus in coastal shelter forests of south-eastern China where it acts as a coastal windbreak and stabilizes sand (Zhong et al., 2001; Zhong et al., 2010). Meanwhile, it also forms a symbiosis with the actinomycete Frankia in its natural habitat, forming root nodules and fixing nitrogen from air. Casuarina glauca and Casuarina equisetifolia are highly salt-tolerant species (Aswathappa et al., 1986). A previous study showed that C. equisetifolia seedlings can survive in 
$87500 \mathrm{mM} \mathrm{NaCl}$ solution and even form root nodules in $300 \mathrm{mM} \mathrm{NaCl}$ solution (Tani \& Sasakawa 88 2003). The symbiotic system between C. equisetifolia seedlings and Frankia Ceql strain also 89 shows high tolerance to salt (Tani \& Sasakawa, 2003). Salt tolerance of some C. equisetifolia clones is related to the rate of germination, seedling height, and proline content (Wu et al., 2010). Recently, a few studies have attempted to explain the mechanism of physiological and molecular responses to salt stress in Casaurina. Under salt stress, proline accumulation occurrs to adjust the osmotic pressure; however, glycine betaine, other amino acids, and total sugars in $C$. equisetifolia remain unchanged (Selvakesavan et al., 2016; Tani \& Sasakawa, 2010). Similarly, C. glauca tolerates high levels of salinity by changing the levels of some neutral sugars, proline, and ornithine (Jorge et al., 2017). In addition, greater amounts of $\mathrm{Na}^{+}$are adsorbed over the roots under salt stress, and expression of $N H X$ and $S O S$ genes in roots helps to maintain $\mathrm{K}^{+}$balance, an essential part of the response to excess salt in C. equisetifolia (Fan et al., 2018). However, the unique strategies adopted by these plants for dealing with salinity and the salt-tolerance mechanisms of these species remain unclear.

The emergence of sequencing technology directly and profoundly revealed the deep information of nucleic acid molecules, and provided a decisive technical means for further exploration of gene structure and function. Fortunately, the recent publication of the genome of C. equisetifolia (Ye et al., 2019) provides valuable information for studying such mechanisms. The obtained sequencing data were compared and spliced with the reference genome. Furthermore, annotation and description of transcripts based on genomic data. Transcriptome analysis enables us to identify differentially expressed genes (DEGs) by providing comprehensive mRNA profiles.

Sodium sensors in roots allow plants to respond quickly to stress, such as the rapid saltspecific response in roots and the rapid, sodium-specific effect of salt on root growth direction (salt solubility) (Choi et al., 2014; Galvan-Ampudia et al., 2013). Roots of C. equisetifolia are tolerant of salt stress in saline soil (Tani \& Sasakawa, 2003; Fan et al., 2018). However, there are few studies on the response mechanism in C. equisetifolia roots under salt stress. The present study therefore focused on the cell structure and a comprehensive transcriptome analysis of $C$. equisetifolia roots exposed to salinity in the form of a $200 \mathrm{mM} \mathrm{NaCl}$ solution for varying durations. The specific objectives were (1) to obtain an overview of the changes over time in $C$. equisetifolia roots under salt stress to complement the insights into the molecular mechanisms of salt tolerance and alterations in root structure in plants, and (2) to identify a number of candidate genes that can be exploited in breeding for enhanced salt tolerance.

\section{Material and methods}




\section{Plant material and salt stress}

The C. equisetifolia clone A8 was preserved and cultivated by the Research Institute of Tropical Forestry, Chinese Academy of Forestry, Guangzhou. The method refers to previous studies (Jiang \& Deyholos, 2006; Kawasaki et al., 2001), rooted cuttings of C. equisetifolia clone A 8 cultured in a growth chamber for 8 weeks were prepared for the experiment. Their roots were washed and the plants were transferred to containers filled with clean water and allowed to grow for 2 weeks until new roots appeared. Plants were then transferred to $1 / 2$ Hoagland solution containing $200 \mathrm{mmol} \mathrm{NaCl} \mathrm{L}-1$ based on a previous study (Fan et al., 2018) and allowed to grow for varying durations. The solution was replaced with fresh solution every day. Roots were harvested following $0,1,6,24$, or $168 \mathrm{~h}$ of salt treatment (Jiang \& Deyholos, 2006) and stored at $-80{ }^{\circ} \mathrm{C}$ until further analysis. The experiment was arranged such that all samples were harvested at the same time. Three replicates were processed at time point, with three individuals in each replicate. Root samples were finely ground, and $1.0 \mathrm{~g}$ of the plant material was digested with concentrated $\mathrm{HNO}_{3}$ in a microwave digestion system (Mars 5, CEM Corporation, Matthews, North Carolina, USA). Inductively coupled plasma emission spectrometry (ICP-oes, Varian Vista-Pro RL) was used to determine the contents of $\mathrm{Na}^{+}, \mathrm{K}^{+}$and $\mathrm{Cl}^{-}$in the extract. These experiments were repeated at least in triplicate, and singnificant differences between mean values were analyzed using one-way ANOVA: the software employed was IBM SPSS Statistics ver. 19 for Windows.

\section{Preparation and observation of tissue morphology and ultrastructure}

Newly produced roots from the same position on each seedling were selected, cut into pieces approximately $1-2 \mathrm{~mm}^{2}$, and fixed in $0.1 \mathrm{M}$ phosphate buffer $(\mathrm{pH} 7.2)$ containing $2 \%$ glutaraldehyde and $2.5 \%$ paraformaldehyde. Root samples were washed six times with $0.1 \mathrm{M}$ phosphate buffer, fixed in $1 \%$ osmium tetroxide for $4 \mathrm{~h}$, and washed again with $0.1 \mathrm{M}$ phosphate buffer. Fixed root samples were then dehydrated and embedded in a flat mold using EPON812 resin. Semi-thin sections $(1 \mu \mathrm{m})$ and ultrathin sections $(80 \mathrm{~nm})$ were cut with an ultramicrotome (Leica EM UC7). The semi-thin sections were stained with toluidine blue and the cell structure was examined under a light microscope (Olympus AX70). Ultrathin sections were stained with $4 \%$ uranyl acetate and $\%$ lead citrate and were examined under a transmission electron microscope (JEM-1010; JEOL, Tokyo, Japan) operating at $100 \mathrm{kV}$.

\section{Extraction and purification of RNA}

New roots were collected from each individual plant and stored in liquid nitrogen at $-80{ }^{\circ} \mathrm{C}$ prior to RNA extraction. Total RNA from each sample was isolated separately using an RN38 
154

155

156

157

158

159

160

161

162

163

164

165

166

167

168

169

170

171

172

173

174

175

176

177

178

179

180

181

182

183

184

185

EASYspin plus Plant RNA kit (Aidlab Biotech, Beijing, China) following the manufacturer's instructions. Purified RNA was quantified using a NanoDrop 2000 spectrophotometer (ThermoFisher Scientific, Wilmington, Delaware, USA), and RNA integrity was evaluated using an Agilent 2100 Bioanalyzer (Agilent Technologies, Santa Clara, California, USA). Three replicates were processed at time point, with three individuals in each replicate. For each sample, at least $20 \mu \mathrm{g}$ of total RNA was sent to Suzhou Encode Genomics Bio-technology Co., Ltd, for Illumina sequencing. Meanwhile, one copy of each RNA sample was kept in the $-80{ }^{\circ} \mathrm{C}$ refrigerator for quantitative reverse-transcription polymerase chain reaction (qRT-PCR) experiments. Based on the manufacturer's instructions, 1-2 $\mu \mathrm{g}$ of total RNA was used as a template in RT reactions with SuperScript III reverse transcriptase (Invitrogen; Thermo Fisher Scientific).

\section{mRNA-Seq experiment and transcriptome assembly}

Ten samples were collected and labelled as follows to reflect the duration of stress and replication: control -1, control -2, 1h-1, 1h-2, 6h-1, 6h-2, 24h-1, 24h-2, 168h-1, and 168h-2.

After sequencing, the raw sequence data were initially processed to obtain clean reads by removing adapter sequences and low-quality sequences. The genomic sequence of Casuarina and the corresponding GFF file were downloaded from the Casuarina SMRT database (http://forestry.fafu.edu.cn/db/Casuarinaceae/index.php). Reads of samples were aligned to the corresponding reference genome using the software package HISAT2 (Daehwan et al., 2015) with default parameters. The sam files were converted into bam files and sorted with default parameters using SAMtools, and the ratio of mapped reads to references sequences in each data set was calculated by applying the flagtool command in SAMtools.

\section{Transcript abundance and differentially expressed genes}

Raw read counts for each transcript were calculated using Htseq-count and normalized to transcripts per million (TPM). TPM $\mathrm{i}_{\mathrm{i}}=\left(\mathrm{N}_{\mathrm{i}} / \mathrm{L}_{\mathrm{i}}\right) * 10^{6} / \mathrm{sum}\left(\mathrm{N}_{\mathrm{i}} / \mathrm{L}_{\mathrm{i}}+\ldots \ldots+\mathrm{N}_{\mathrm{m}} / \mathrm{L}_{\mathrm{m}}\right) ; \mathrm{N}_{\mathrm{i}}$ represents the reads mapping to the $\mathrm{i}$-th gene, and $\mathrm{L}_{\mathrm{i}}$ represents the total length of the exons of the $\mathrm{i}$-th gene. DEGs in the different treatments were analyzed using $R$ (DESeq2). Raw counts were fed to DESeq2, and only those genes in which the $\mid \log 2$ (fold change) $\mid$ was greater than 1 and the false discovery rate was less than 0.01 were identified as DEGs. The expression patterns of the DEGs were made visible using $R$ pheatmap. Differentially expressed transcription factors (TFs) were predicted by submitting the DEGs to the PlantTFDB 4.0 database (http://plant tfdb.cbi.pku.edu.cn/) (Jin et al., 2017). 
186

187

188

189

190

191

192

193

194

195

196

197

198

199

200

201

202

203

204

205

206

207

208

209

210

211

212

213

214

215

216

217

GO analysis was carried out for the DEGs using the agriGO database (http://systemsbiology.cau.edu.cn/agriGOv2/index.php), and the $P$ values were corrected to control falsely rejected hypotheses during the GO analysis. GO annotations of 23,397 genes from the genome of $C$. equisetifolia were taken as the reference set, and GO annotations of DEGs were taken as the test set. DEGs were classified and analyzed statistically according to three major functional modules, namely molecular function, biological process, and cellular component, and functional annotation of the DEGs was conducted according to these three modules. Paralogs and orthologs were identified by running a BLASTN (Altschul et al., 1997) for all nucleotide sequences for each species, based on the same method described by Blanc and Wolfe.

\section{Quantitative reverse-transcription polymerase chain reaction}

Total RNA samples used in transcriptome sequencing were also used for qRT-PCR. Reactions were performed on an Applied Biosystems 7500 Real-Time PCR using a SYBR Premix Ex Taq ${ }^{\mathrm{TM}}$ kit (TaKaRa, Japan) following the manufacturer's instructions. The combination CaeUBC and CaeEFl $\alpha$ was used as an internal control (Fan et al., 2017). Primers were designed using Primer Premier ver. 5.0 to allow for amplification of 80-200 bp products. Gene names, sequences, and the primers used for qRT-PCR analysis are listed in Table S1. Thermal cycling conditions were $30 \mathrm{~s}$ at $95^{\circ} \mathrm{C}$ followed by 40 cycles of $5 \mathrm{~s}$ at $95{ }^{\circ} \mathrm{C}$ and $34 \mathrm{~s}$ at $60{ }^{\circ} \mathrm{C}$. A dissociation curve was obtained by heating the amplicon from $60{ }^{\circ} \mathrm{C}$ to $95{ }^{\circ} \mathrm{C}$. Each sample was analyzed at least three times. Standard curves were established for all genes investigated using a series of amplicon dilutions. Relative expression level was calculated using the $2^{-\Delta \Delta \mathrm{CT}}$ method (Schmittgen et al., 2008).

\section{Availability of data and materials}

Raw Illumina sequence data were deposited in the Short Read Archive of the NCBI database (project accession number SRP064226).

\section{Results}

\section{Morphological changes in roots}

We previously studied $C$. equisetifolia clone A8 under different $\mathrm{NaCl}$ concentrations (Fan et al., 2017). The number of lateral roots was decreased under 200, 400, or $600 \mathrm{mM} \mathrm{NaCl}$ treatment, while etiolated and wilted leaves and black and decayed roots were observed under $400 \mathrm{mM}$ and $600 \mathrm{mM} \mathrm{NaCl}$ treatments. To gain more accurate insight into the salt response mechanism and identify DEGs associated with salt stress rather than senescence or death, we performed the salt 
218

219

220

221

222

223

224

225

226

227

228

229

230

231

232

233

234

235

236

237

238

239

240

241

242

243

244

245

246

247

248

249

250

251

stress treatment of $C$. equisetifolia under $200 \mathrm{mM} \mathrm{NaCl}$.

As the duration of exposure to stress increased, so did the extent to which root growth and formation of lateral roots were inhibited. Grey roots (white boxes) were also observed at 24 and $168 \mathrm{~h}$ (Fig. 1), and no nodule formation was observed. Similarly, Ngom et al. (2016) reported that nodule formation did not occur in seedings inoculated with $\mathrm{Ccl} 3$ or $\mathrm{CeD}$, at $\mathrm{NaCl}$ concentrations above 100 and $200 \mathrm{mM}$, respectively. Root microstructure in the cortex, vascular system, and aerenchyma cells was almost similar under $0 \mathrm{~h}$ and $1 \mathrm{~h}$ treatments (Fig. 2). However, cell disfiguration in the epidermis became apparent after $6 \mathrm{~h}$. Some epidermal cells were shed under the $24 \mathrm{~h}$ treatment, with slight plasmolysis in some cortex cells; in addition, the pericycle cells continued to shrink, and the epidermal cells became separated from the cortex cells. After $168 \mathrm{~h}$ of treatment, the roots shriveled even further and became disfigured. Epidermal cells became detached, and more aerenchyma tissue was produced by the cortex cells under salt stress (Fig. 2). The epidermal cells were thickened considerably and were tightly packed together; the endo-epidermis, which forms a thicker barrier, protects the aerenchyma from damage. The protective gap produced between cortex cells and pericycle cells was widest at $168 \mathrm{~h}$ of treatment, and the cells neighbouring the pericycle cells were thicker, forming a second barrier created by the root.

\section{Ultrastructural changes in roots}

To analyze the changes in cell structure in roots of $C$. equisetifolia in response to salt stress in greater detail, we also performed ultrastructural analysis. Because the changes observed under $1 \mathrm{~h}$ and $6 \mathrm{~h}$ treatments were similar, our analysis focused on the $6 \mathrm{~h}$ treatment. As shown in Fig. 3 , epidermal cells with abundant accumulation of cytoplasm around the cell wall were closely connected in control plants. With increasing duration of exposure to salinity, marked changes in the shapes of epidermal cells and cortical cells appeared (Fig. 3 and Fig. 4). The number of mitochondria increased in cortical cells and stele cells under the $24 \mathrm{~h}$ treatment but not under the other treatments (Fig. 4 and Fig. 5). Nevertheless, no significant plasmolysis was observed in stele cells (Fig. 5). After $168 \mathrm{~h}$ of $\mathrm{NaCl}$ treatment, plasmolysis was evident and the cell wall of the epidermal cells became loose; some exterior parts of the cell wall were isolated and desquamated, the mitochondrial membrane structure showed deterioration, and there was slight disorganization of the matrix and cristae in epidermal cells and cortical cells (Fig. 3 and Fig. 4). However, stele cells with intact membranes and organelles including the cell wall, endoplasmic reticulum, mitochondria, nucleus, and vacuole were also observed (Fig. 5). In addition, cessation of cell growth and inhibition of cell division were also evident, as indicated by the number of cells and accumulation of biomass in the pericycle cells. These results indicate that $C$. 
252

253

254

255

256

257

258

259

260

261

262

263

264

265

266

267

268

269

270

271

272

273

274

275

276

277

278

279

280

281

282

283

equisetifolia initiates an adaptive response to salinity stress in its roots.

\section{Changes in ions content}

With the increasing of salt stress, the content of sodium and chloride ions in C. equisetifolia roots increased, with the content of chloride ions obviously higher than that of sodium ions. When the treatment time reached $168 \mathrm{~h}$, the content of $\mathrm{Cl}^{-}$was as high as $59.903 \mathrm{~g} . \mathrm{kg}^{-1}$ and the content of $\mathrm{Na}^{+}$was $33.50 \mathrm{~g} . \mathrm{kg}^{-1}$. Compared with the control group, the content of potassium decreased slowly between $1 \mathrm{~h}\left(14.71{\mathrm{~g} . ~ \mathrm{~kg}^{-1}}^{-1}\right)$ and $24 \mathrm{~h}\left(10.14 \mathrm{~g} . \mathrm{kg}^{-1}\right)$ after initiation of salt treatment, while the content of potassium was significantly lower after $168 \mathrm{~h}\left(1.63{\mathrm{~g} . ~ \mathrm{~kg}^{-1}}^{-1}\right)$ of salt treatment (Table 1). In addition, the $\mathrm{K}^{+}: \mathrm{Na}^{+}$ratio showed a clear decrease with salt treatment time. In the control group, the $\mathrm{K}^{+}: \mathrm{Na}^{+}$value was 3.12 ; after $1 \mathrm{~h}$ of treatment, the ratio was 1.15 ; with increasing treatment time, the ratio continued to decrease, reaching 0.05 at $168 \mathrm{~h}$.

\section{Alignment and assembly of RNA-Seq datasets}

We performed transcriptome analysis based on high-throughput RNA-Seq. In total, $561,652,970$ clean reads were generated, and the number of clean reads per library ranged from $68,520,708$ to $94,889,166$. The clean reads were mapped to the C. equisetifolia reference genome (Ye et al., 2019) with mapping rates ranging from $77.06 \%$ to $81.52 \%$ (Table S2). Scatter plots of data from all samples showed that the samples formed two clusters: samples from the $1 \mathrm{~h}$ and $6 \mathrm{~h}$ treatments were clustered in one group and showed a relatively close relationship with the control $(0 \mathrm{~h})$, thus representing the early stages of the response, whereas samples from the 24 and $168 \mathrm{~h}$ treatments were clustered in a second group, representing the later stages of response (Fig. S1A). Pair-wise values of Pearson's correlation of expression between biological replicates ranged from 0.985 to 0.999 (Fig. S1B), and correlations of expression values between treatment and control samples indicated that the early-stage samples were closely related, with only a moderate difference ( $R=0.792$ for $1 \mathrm{~h}$ vs $0 \mathrm{~h}$ and $R=0.723$ for $6 \mathrm{~h}$ vs $0 \mathrm{~h}$ ) (Fig. S1C). The scatter of gene expression values and the low correlations $(R=0.650$ and $R=0.339$ ) revealed that the number of DEGs changed under the $24 \mathrm{~h}$ and $168 \mathrm{~h}$ treatments. These results indicate that the late-response stage was not simply the result of repression but also involved activation of new groups of genes associated with salt stress.

\section{Identification of DEGs and gene enrichment analysis under salt stress}

DEGs were also detected as exposure to stress became more prolonged. A total of 10,738 DEGs were identified (Table S3-1): 2399 in the $1 \mathrm{~h}$ treatment, 5668, at $6 \mathrm{~h}, 7660$ at $24 \mathrm{~h}$, and 6849 at $168 \mathrm{~h}$ compared with the control (0 h) (Fig. S2 and Table S3-2 to Table S3-5). There 
284

285

286

287

288

289

290

291

292

293

294

295

296

297

298

299

300

301

302

303

304

305

306

307

308

309

310

311

312

313

314

315

316

317

were 523, 499, 1535, and 1349 DEGs specific to each time point, whereas 1103 DEGs were common to all the four salt treatments (Fig. 6 and Table S3-6 to Table S3-11). This result indicates that complex transcriptional regulatory events occurred during the later stages of the salt treatment.

GO enrichment using a $P$ value of $\leq 0.05$ as the cut-off identified $401 \mathrm{GO}$ terms enriched during the entire duration of salt stress (Table S4-1). A large number of DEGs were associated with biological processes (209 terms) and molecular functions (157 terms) under salt stress. The enriched categories in C. equisetifolia roots consisted of genes involved in signaling, transport, metabolism, regulation, and development. To gain further insight into the biological processes associated with the observed temporal changes, GO enrichment analysis was performed at each of the time points (Table S4-2 to Table S4-5). Many categories associated with signal transduction and DNA were enriched in the $1 \mathrm{~h}$ and $6 \mathrm{~h}$ treatments. The biological processes represented by these ontologies were significantly less enriched during the later stages of salt stress (Fig. 7 and Table S4-2 to Table S4-5). This implies that salt stress triggered numerous signal transduction pathways and DNA replication and repairs processes within $1 \mathrm{~h}$ and $6 \mathrm{~h}$ of the onset of salt stress. Salt stress induced the responses from multiple hormones in $C$. equisetifolia, including ABA, JA, gibberellin, and auxin (Fig. 7). Stress-response ontology terms enriched at $1 \mathrm{~h}$ and/or $6 \mathrm{~h}$ indicated that the roots of $C$. equisetifolia can respond immediately to salt stress by activating stress-response genes. It is also noteworthy that some ontologies representing transport, cell development, and growth were enriched at 24 and/or $168 \mathrm{~h}$ (Fig. 7), and that DEGs identified at the later stages (24 and $168 \mathrm{~h}$ ) were specifically enriched in ontologies associated with death, corresponding to root cell apoptosis in the earlier experiment (Fig. 7). Both oxidation and detoxification GO terms, which are associated with eliminating ROS induced by the stress, were enriched throughout.

\section{Response of DEGs to salt stress in $C$. equisetifolia}

To obtain an overall view of the expression profiles of the 10,738 DEGs identified in $C$. equisetifolia, we constructed a heat map using $R$ (Pheatmap) (Table S5). The transcriptome responses of $C$. equisetifolia treated with salt stress for different lengths of times are shown in Fig. 8A. Oxidase superfamily proteins, protein kinases, MAPK signaling cascades, ion homeostasis, and other related genes were identified during this process. All DEGs were divided into four clusters based on their expression patterns. Cluster 1 comprised MAPK4 (CCG019781), calcium-transporting ATPase (CCG010076 and CCG005018), HKT1 (CCG006526 and CCG006527), and CHX (cation/hydrogen exchanger) (CCG009112 and CCG013892), which were quickly induced within $1 \mathrm{~h}$ of treatment and responded to salt stress immediately. Cluster 2 
318

319

320

321

322

323

324

325

326

327

328

329

330

331

332

333

334

335

336

337

338

339

340

341

342

343

344

345

346

347

348

349

350

351

comprised CIPK21 (CBL protein-interacting protein kinases) (CCG001663), CDPK2 (calciumdependent protein kinase) (CCG001182), VQ motif-containing (CCG005740 and CCG004208) and GST25 (glutathione S-transferase) (CCG015479, CCG015480, and CCG015481), which were induced at $6 \mathrm{~h}$ and remained upregulated as the duration of stress increased. Both these above clusters also included $N H X$ (sodium hydrogen exchanger) genes such as $N H X 1$ (CCG027771 and CCG003145) and NHX2 (CCG028406). Cluster 3 comprised SOS2 (CCG023938), MAPK9 (CCG029210), glutathione S-transferase (CCG013823) and CDPK1 (CCG013990), which were upregulated at $6 \mathrm{~h}$ of treatment and peaked at $24 \mathrm{~h}$. It is noteworthy that Cluster 4 comprised HAK5 (CCG012758), KUP6 (CCG017938), and some genes related to cell death (CCG014816, CCG014814 and CCG013802), the expression of which was specifically induced under the $168 \mathrm{~h}$ treatment (Fig. 9A and Fig. 9B). Several genes were selected for validating the transcriptome data using qRT-PCR analysis, and these showed similar expression patterns to those indicated by TPM values (Fig. S2).

We also identified TFs differentially expressed in response to salt stress. A total of 689 TFs were distributed among 44 families in $C$. equisetifolia (Table S6). The majority of TF genes belonged to the $b H L H, M Y B, N A C, A P 2 / E R F, W R K Y, b Z I P, H D-Z I P$, GRAS, and $C 2 H 2$ families (Fig. 8B). We identified $99 M Y B, 44 N A C, 75 A P 2 / E R F$, and $43 W R K Y$ genes, which function under salt stress and also under biotic stress (Table S6). Among TF families, the number of genes belonging to the $M Y B$ superfamily was the largest, similar to the potential transcriptional regulatory factors in the symbiosis of Casuarina and Rehmannae radiosurface (Diédhiou et al., 2014). For example, MYB2 (CCG011536), which is involved in the induction of salt-responsive genes that are induced by ABA (Dubos et al., 2010), and WRKY70 (CCG020989), which modulates tolerance to osmotic stress by regulating stomatal aperture (Jing et al., 2013), were also induced under salt stress in roots of $C$. equisetifolia. Additionally, most $A P 2 / E R F, W R K Y$, and $b Z I P$ genes grouped into Cluster 2, which were up-regulated during the later stages of salt treatment. It should also be noted that $L B D, G R A S, A R F$, and $G R F$ genes involved in plant growth and development showed differential expression in this study. For example, Scarecrowlike, a GRAS protein (CCG016614), and zinc-finger protein 5 (CCG017923), which mainly control the coordination of root cell elongation and development (Heo et al., 2011; Xie et al., 2019), also responded to salt stress in C. equisetifolia. We speculate that these genes contribute to the response to salt stress either directly or by resisting negative effects through regulating growth and development under long-term salt stress.

\section{Discussion}

Salinity is one of the extreme environments that limit plant growth. C. equisetifolia, which 
352

353

354

355

356

357

358

359

360

361

362

363

364

365

366

367

368

369

370

371

372

373

374

375

376

377

378

379

380

381

382

383

384

385

can tolerate salinity, is used for creating shelter forests in coastal belts. However, few studies have examined the mechanism of its adaptation to salt sress in detail. In the present study, although $200 \mathrm{mM} \mathrm{NaCl}$ did not affect the growth of $C$. equisetifolia seedlings substantially, longer exposure to salinity inhibited root growth and the formation of new lateral roots; the roots also turned dark, cells were shed, and epidermal cells showed plasmolysis (Fig. 1)-symptoms that have been reported in other plant species as well (Tu et al., 2014). With increasing duration of salt treatment, the structure of root cells changed, but remained intact. Most of the cells in the outer epidermis died and were shed, which was a different response from that seen in other plants such as rice (Céccoli et al., 2011).

We identified fewer DEGs at 1 and $6 \mathrm{~h}$ compared with $0 \mathrm{~h}$ than at 24 and $168 \mathrm{~h}$, as ascertained through transcriptome analysis (Fig. 6). Histological examination of the corresponding tissues showed that morphological changes became more obvious with increasing duration of salt treatment (Fig. 2). GO enrichment analysis annotated genes associated with signaling, stress response, hormone, and transport ontologies during the early stages of salt stress ( $1 \mathrm{~h}$ and $6 \mathrm{~h}$ ) (Fig. 7). This suggests that genes related to signaling, transport, hormones and to stress responsees are initiated immediately in roots of $C$. equisetifolia exposed to salt stress. Earlier studies reported similar responses, namely rapid and dynamic changes in root and shoot growth in plants exposed to salinity (Passioura \& Munns, 2000; Munns, 2002). However, ultrastructural analysis showed slight plasmolysis in epidermal cells after $6 \mathrm{~h}$ of exposure to salt. These initial changes in growth were driven by the osmotic component of salt stress, which immediately affects the water status of the plant, preventing cell elongation. Within several hours of treatment, partial recovery of growth occurred owing to the uptake of inorganic ions and the biosynthesis of compatible osmolytes, which reduce the water potential of cells until cell expansion can resume (Yu et al., 2013).

It is particularly noteworthy that under the 24 and $168 \mathrm{~h}$ salt treatments, DEGs were enriched for metal ion and sodium ion transport GO terms (Fig. 7). We identified 26 DEGs related to ion transport (Fig. 9A). Plants are known to adapt to salt stress through the SOS pathway to maintain ion balance in cells (Zhu, 2003; El Mahi et al., 2019). Of the 26 DEGs, SOS 2 was up-regulated at $6 \mathrm{~h}$ and reached its maximum expression at $24 \mathrm{~h}$, and NHX7 (SOS1) genes responded positively to salt stress. Some TFs such as $b Z I P$, which activates the expression of genes involved in cytoplasmic ion homeostasis, such as the $\mathrm{Na}^{+}$transporter $H K T 1$ and the $\mathrm{Na}^{+} / \mathrm{H}^{+}$anti-transporter SOS1 in Arabidopsis (Yang et al., 2009), were also expressed in $C$. equisetifolia roots under salt stress. Two HKTs were identified among the DEGs (Fig. 9A). Even more noteworthy is the fact that sodium and chloride content increased significantly after $24 \mathrm{~h}$ of 
386

387

388

389

390

391

392

393

394

395

396

397

398

399

400

401

402

403

404

405

406

407

408

409

410

411

412

413

414

415

416

417

418

419

salt treatment (Table 1). Maintaining potassium balance is an essential part of plant response to salt stress. AtHKTl regulates $\mathrm{K}^{+}$state (Wang et al., 2018), whereas $H v H K T 1 ; 5$ in stele cells, negatively regulates salt tolerance in barley (Huang et al., 2020). Overexpression of OsHAK5 increases the $\mathrm{K}^{+}: \mathrm{Na}^{+}$ratio and tolerance to salt stress in rice seedlings (Yang et al., 2014). In the present study, the expression of most members of the $H A K$ genes family was up-regulated and potassium concentration decreased slowly between $1 \mathrm{~h}$ and $24 \mathrm{~h}$ after initiation of salt treatment. These results imply that $H A K$ is involved in maintaining $\mathrm{K}^{+}: \mathrm{Na}^{+}$homeostasis in response to salt stress in C. equisetifolia. Taken together, our results suggest that ion transport plays an important role in the response of $C$. equisetifolia to long-term salt stress. Two $H K T$ genes were identified among the DEG, and some $H A K$ genes were highly expressed after $168 \mathrm{~h}$ of salt treatment. $H K T$ and $H A K$ genes can therefore be used as candidates to study the molecular function of salt tolerance in C. equisetifolia.

It is well known that plants accumulate more ROS under salt stress. The DEGs associated with salinity treatment were greatly enriched in GO terms related to ROS-related biological processes and molecular functions (Table S4), such as the hydrogen peroxide catabolic process and the oxidation-reduction process. Heterologous expression of GhWRKY41 in Nicotiana benthamiana was reported to enhances salt tolerance by regulating ROS scavenging (Chu et al., 2015). Furthermore, bHLH92 (CCG027461) and WRKY33 (CCG011999 and CCG003169) play a regulatory role in ROS detoxification through glutathione S-transferases and peroxidase (Miller et al., 2010), suggesting that these TFs mediate ROS scavenging and oxidative stress-induced signaling pathways. Additionally, ROS might act as a signal molecule controlling plant programmed cell death (PCD) (Gechev et al., 2005; Petrov et al., 2015), and salt treatment is known to induce PCD in root tips (Chen et al., 2009) and leaves (Ambastha et al., 2017) in rice. Salt stress induces an increase in ROS before PCD in tobacco protoplasts, pointing to an association between oxidative damage and PCD (Lin et al., 2006). In the present study, GO terms associated with ROS-related biological processes were enriched throughout the salinity treatment, whereas PCD-related genes were enriched among DEGs during the later stages (Fig. 7). Therefore, we conclude that generation of ROS is activated under salt stress, initiating PCD, which is important for regulating the response of $C$. equisetifolia to salt stress.

Ultrastructural analysis revealed significant changes in cell structure after $168 \mathrm{~h}$ of salt stress (Fig. 2). Correspondingly, DEGs identified at the late time points ( $24 \mathrm{~h}$ and $168 \mathrm{~h}$ ) were specifically enriched in ontologies associated with cell death, indicating that root cell apoptosis is part of the response to salt stress (Fig. 7). PCD is an important part of the response to salt stress, ensuring the plant has enough time to activate mechanisms for adapting to stress. Under non-

Peer) reviewing PDF | (2021:02:58311:2:0:NEW 2 Aug 2021) 
420

421

422

423

424

425

426

427

428

429

430

431

432

433

434

435

436

437

438

439

440

441

442

443

444

445

446

447

448

449

450

451

452

453

454

lethal conditions, PCD induced in severely salt-stressed roots removes most of the saltsusceptible cells, which are subsequently replaced with cells better adapted to the stress (Kacprzyk et al., 2011). In rice, root cell death under salinity starts from epidermal and cortical cells and progresses to the endodermis and stele to minimize the adverse effects of stress. The dead cells prevent the influx of excess salt ions into the stele and into shoots, leading to larger amounts of salt being excluded (Liu et al., 2006). Similar results were also obtained in the present study: epidermal cells were shed and a more compact layer of cells formed after $168 \mathrm{~h}$ of salt treatment (Fig. 2). After $24 \mathrm{~h}$ and $168 \mathrm{~h}$ of treatment, plasmolysis was seen in both epidermal cells and cortical cells, and mitochondria were seriously damaged (Fig. 3 and Fig. 4). Temporal trends in enrichment of GO terms among DEGs corresponded closely with observed changes in root morphology in response to salt stress. Furthermore, 15 PCD-related genes were identified as thaumatin-like proteins (TLPs), most of which were upregulated at $168 \mathrm{~h}$ (Fig. 9B). TLP genes can be induced by salicylic acid (SA) or JA hormone signaling, thus playing an important role in plant stress defense processes (Rout et al., 2016; Sun et al., 2020). Lopes et al. (2019) reported that TLP genes have selective anticandidal activity, inducing apoptosis via a membrane receptor (Lopes et al., 2019). DEGs identified at $168 \mathrm{~h}$ were specifically enriched in ontologies associated with the SA metabolic process and JA- mediated signaling pathways. These results showed that $T L P$ expression is regulated by SA and JA in C. equisetifolia under salt stress, leading to PCD. $T L P$ genes can also be used as candidates for studying the molecular function of salt tolerance in C. equisetifolia.

Previous studies have shown that C. equisetifolia tolerance to high salt concentrations is innate (Scotti-Campos et al., 2016; Selvakesavan et al., 2016) and that in vitro salt tolerance of Frankia strains has no correlation with the salt tolerance of C. equisetifolia under salt-stressed conditions (Ngom et al., 2016). Furthermore, nitrogenase activity in nodules is insignificant at $200 \mathrm{mM} \mathrm{NaCl}$ (Duro et al., 2016; Mansour et al., 2016). Similarly, $100 \mathrm{mM} \mathrm{NaCl}$ concentration has a significant inhibitory effect on nodule function in Elaeagnus commutate (Shao et al., 2020). Previous studies have revealed that salt tolerance in C. glauca is linked to photosynthetic, primary metabolic adjustments and to an effective antioxidant machinery (Graça et al., 2019; Batista-Santos et al., 2015; Jorge et al., 2019). Our research results showed that the sodium content of C. equisetifolia roots was significantly increased (30.903 g. kg-1) after $24 \mathrm{~h}$ of salt treatment. C. equisetifolia can sequester $\mathrm{Na}^{+}$in root tissues to prevent sodium transfer to the shoot (Fan et al., 2017), implying that $H K T, H A K$, and $N H X$ are involved in maintaining $\mathrm{K}^{+}: \mathrm{Na}^{+}$ homeostasis in C. equisetifolia in response to salt stress. Structural analysis revealed more obvious deformation of the cell membrane with increasing duration of salt stress (Fig. 2). Meanwhile, 15 PCD-related genes were induced by SA or JA to participate in the salt stress 
455

456

457

458

459

460

461

462

463

464

465

466

467

468

469

470

471

472

473

474

475

476

477

478

479

480

481

483

484

482 Grant Disclosures:

response. Interestingly, selection of appropriate fungal strains is crucial for improving $C$. equisetifolia performance in saline soils (Djighaly et al., 2018). The effect of Frankia symbiosis on salt tolerance of $C$. equisetifolia will be our next research focus.

\section{Conclusion}

Soil salinity is a severe environmental constraint on plant growth. Roots of C. equisetifolia were exposed to $200 \mathrm{mM} \mathrm{NaCl}$ solution for $0,1,6,24$, and $168 \mathrm{~h}$. Epidermal cells sloughed off and a more compact layer of cells formed after $168 \mathrm{~h}$ of treatment, while potassium concentration remained relatively stable. Ultrastructural analysis revealed cell deformation and mitochondrial damage in the epidermis and endodermis but less damage in stele cells. A total of 10,378 DEGs were identified through transcriptome analysis. Oxidative stress and detoxification increased throughout the treatment period, and expression of genes related to these processes was upregulated. Salt stress led to higher $\mathrm{Na}^{+}$content in C. equisetifolia roots. We determined that, in order to prevent excessive accumulation of $\mathrm{Na}^{+}$, which is toxic to cells, some genes identified in the present study, including those encoding $\mathrm{Na}^{+} / \mathrm{H}^{+}$transporters, $\mathrm{K}^{+}$transporters, and potassium channel proteins, were upregulated in response to salt stress. As stress continued, specific ontologies associated with cell death and PCD were enriched among DEGs, and genes related to these processes were significantly upregulated at $168 \mathrm{~h}$ of salt treatment. Some TFs, such as those belonging to the WRKY and the MYB gene families, were induced under salt stress. In the future, we will focus on candidates including ion transporter-related genes and PCD-related genes and verify their molecular functions using plant trasformation.

\section{Acknowledgements}

We acknowledge Professor Mengzhu Lu's suggestions about the experimental design. We also thank Dr. Min Li for his critical reading of this manuscript.

\section{Funding}

This work was supported by grants from the Specific Program for National Non-profit Scientific Institutions (CAFYBB2018ZB003) and project funded by the National Natural Science Foundation of China (Grant No. 31770716).

483 The following grant information was disclosed by the authors:

48 Specific Program for National Non-profit Scientific Institutions: CAFYBB2018ZB003 
485

486

487

488

489

490

491

492

493

National Natural Science Foundation of China: 31770716

\section{Competing interests}

The authors declare no financial or commercial conflict of interest.

\section{Author contributions}

Yujiao Wang performed the experiments, analyzed the data, prepared figures and tables, reviewed the draft, and approved the final manuscript.

Jin Zhang conceived and designed the experiments, and approved the final manuscript.

Zhenfei Qiu performed the experiments, analyzed the data, and approved the final manuscript.

Bingshan Zeng conceived and designed the experiments, and approved the final manuscript.

Yong Zhang participated in the experiment design, revised and approved the final manuscript.

Xiaoping Wang performed the experiments and approved the final manuscript.

Jun Chen performed the experiments and approved the final manuscript.

Chonglu Zhong conceived and designed the experiments, and approved the final manuscript.

Rufang Deng analyzed the data and approved the final manuscript.

Chunjie Fan conceived and designed the experiments, reviewed the draft, and approved the final manuscript.

\section{Data Availability}

The following information was supplied regarding data availability: The raw data are available in a Supplemental File.

\section{Reference}

Altschul SF, Madden TL, Schäffer A, Zhang J, Zhang Z, Miller W and Lipman DJ. (1997). Gapped BLAST and PSI-BLAST: a new generation of protein database search programs. Nucleic acids research 25, 3389-3402.

Ambastha V, Sopory SK, Tiwari BS, Tripathy BC. 2017. Photo-modulation of programmed cell death in rice leaves triggered by salinity. Apoptosis 22(1):41-56. DOI: 10.1007/s10495-016-1305-7.

Aswathappa N, Bachelard E P. 1986. Ion regulation in the organs of Casuarina species differing in salt tolerance. Functional Plant Biology 13(4):533-545.

Batista-Santos P, Duro N, Rodrigues AP, Semedo JN, Alves P, da Costa M, Graça I, Pais IP, Scotti-Campos P, Lidon FC, Leitão AE, Pawlowski K, Ribeiro-Barros AI, Ramalho JC. 2015. Is salt stress tolerance in Casuarina glauca Sieb. ex Spreng. associated with its 
516

517

518

519

520

521

522

523

524

525

526

527

528

529

530

531

532

533

534

535

536

537

538

539

540

541

542

543

544

545

546

547

548

549

550

551

nitrogen-fixing root-nodule symbiosis? An analysis at the photosynthetic level. Plant Physiol Biochem 96:97-109. DOI: 10.1016/j.plaphy.2015.07.021.

Blanc G, and Wolfe, K.H. 2004. Widespread paleopolyploidy in model plant species inferred from age distributions of duplicate genes. The Plant Cell 16, 1667-1678. DOI: $10.1105 /$ tpc. 021345 .

Boudsocq M, Sheen J. 2013. CDPKs in immune and stress signaling. Trends Plant Sci 18(1):3040. DOI: 10.1016/j.tplants.2012.08.008.

Céccoli G, Ramos JC, Ortega LI, Acosta JM, Perreta MG. 2011. Salinity induced anatomical and morphological changes in Chloris gayana Kunth roots. Biocell 35(1):9-17. DOI: 10.4161/org.7.2.16457.

Chen GH, Yan W, Yang LF, Gai JY, Zhu YL. 2014. Overexpression of StNHXI, a Novel Vacuolar $\mathrm{Na}^{+} / \mathrm{H}^{+}$antiporter gene from Solanum torvum, enhances salt tolerance in transgenic vegetable soybean. Horticulture Environment 55(3):213-221. DOI: 10.1007/s13580-014-0003-z.

Chen S, Polle A. 2010. Salinity tolerance of Populus. Plant Biology 12(2):317-333. DOI: 10.1111/j.1438-8677.2009.00301.x.

Chen X, Wang Y, Li J, Jiang A, Cheng Y, Zhang W. 2009. Mitochondrial proteome during salt stress-induced programmed cell death in rice. Plant Physiology and Biochemistry 47(5):407-415. DOI 10.1016/j.plaphy.2008.12.021.

Chen X, Zhang X, Jia A, Xu G, Hu H, Hu X, Hu L.2016. Jasmonate mediates salt-induced nicotine biosynthesis in tobacco (Nicotiana tabacum L.). Plant Divers 16;38(2):118123. DOI: 10.1016/j.pld.2016.06.001.

Choi WG, Toyota M, Kim SH, Hilleary R, Gilroy S. 2014. Salt stress-induced $\mathrm{Ca}^{2+}$ waves are associated with rapid, long-distance root-to-shoot signaling in plants. Proc Natl Acad Sci USA 111(17):6497-6502. DOI: 10.1073/pnas.1319955111.

Chu X, Wang C, Chen X, Lu W, Li H, Wang X, Hao L, Guo X. 2015. The Cotton WRKY Gene GhWRKY41 Positively Regulates Salt and Drought Stress Tolerance in Transgenic Nicotiana benthamiana. Plos One 11(6): e0157026. DOI: 10.1371/journal.pone.0157026.

Daehwan K, Ben L, L SS. 2015. HISAT: a fast spliced aligner with low memory requirements. Nature methods 12(4):357-360. DOI: 10.1038/nmeth.3317.

Das R, Pandey GK. 2010. Expressional analysis and role of calcium regulated kinases in abiotic stress signaling. Curr Genomics 11(1):2-13. DOI: 10.2174/138920210790217981.

Deinlein U, Stephan AB, Horie T, Luo W, Xu G, Schroeder JI. Plant salt-tolerance mechanisms. 2014. Trends Plant Sci 19(6):371-379. DOI: 10.1016/j.tplants.2014.02.001.

Diédhiou I, Tromas A, Cissoko M, Gray K, Parizot B, Crabos A, Alloisio N, Fournier P, Carro 
552

553

554

555

556

557

558

559

560

561

562

563

564

565

566

567

568

569

570

571

572

573

574

575

576

577

578

579

580

581

582

583

584

585

586

587

588

L, Svistoonoff S, Gherbi H, Hocher V, Diouf D, Laplaze L, Champion A. 2014. Identification of potential transcriptional regulators of actinorhizal symbioses in Casuarina glauca and Alnus glutinosa. BMC Plant Biol 14:342. DOI: 10.1186/s12870014-0342-z.

Djighaly, Pape, Ibrahima, Diagne, Nathalie, \& Ngom, et al. 2018. Selection of arbuscular mycorrhizal fungal strains to improve Casuarina equisetifolia l. and Casuarina glauca sieb. tolerance to salinity. Annals of Forest Science 75: 72. DOI: https://doi.org/10.1007/s13595-018-0747-1

Dubos C, Stracke R, Grotewold E, Weisshaar B, Martin C, Lepiniec L. 2010. MYB transcription factors in Arabidopsis. Trends Plant 15(10):573-581. DOI: 10.1016/j.tplants.2010.06.005

Duro N, Batista-Santos P, MD Costa, et al. 2016. The impact of salinity on the symbiosis between Casuarina glauca Sieb. ex Spreng. and N2-fixing Frankia bacteria based on the analysis of Nitrogen and Carbon metabolism. Plant\&Soil 398:327-337. DOI: 10.1007/s11104-015-2666-3.

El Mahi H, Perez-Hormaeche J, De Luca A, Villalta I, Espartero J, Gamez-Arjona F, Fernandez JL, Bundo M, Mendoza I, Mieulet D. 2019. A Critical Role of Sodium Flux via the Plasma Membrane $\mathrm{Na}^{+} / \mathrm{H}^{+}$Exchanger SOS1 in the Salt Tolerance of Rice. Plant Physiology 180 (2):1046-1065. DOI: 10.1104/pp.19.00324

Fan C, Qiu Z, Zeng B, Li X, Xu SH. 2018. Physiological adaptation and gene expression analysis of Casuarina equisetifolia under salt stress. Biologia Plantarum 62(3):489500. DOI: 10.1007/s10535-018-0799-y.

Fan C, Qiu Z, Zeng B, Liu Y, Li X, Guo G. 2017. Selection of reference genes for quantitative real-time PCR in Casuarina equisetifolia under salt stress. Biologia Plantarum 61 (3):463-472. DOI: 10.1007/s10535-016-0670-y

Galvan-Ampudia CS, Julkowska MM, Darwish E, Gandullo J, Korver RA, Brunoud G, Haring MA, Munnik T, Vernoux T, Testerink C. 2013. Halotropism is a response of plant roots to avoid a saline environment. Curr Biol 23(20):2044-2050. DOI: 10.1016/j.cub.2013.08.042.

Gechev TS, Hille J. 2005 Hydrogen peroxide as a signal controlling plant programmed cell death. The Journal of cell biology 168(1):17-20. DOI: 10.1083/jcb.200409170.

Geng Y, Wu R, Wee CW, Xie F, Wei X, Chan PM, Tham C, Duan L, Dinneny JR. 2013. A spatio-temporal understanding of growth regulation during the salt stress response in Arabidopsis. Plant Cell 25(6):2132-54. DOI: 10.1105/tpc.113.112896.

Gill SS, Tuteja N. 2010. Reactive oxygen species and antioxidant machinery in abiotic stress tolerance in crop plants. Plant Physiology and Biochemistry 48(12):909-930. DOI: 10.1016/j.plaphy.2010.08.016. 
589

590

591

592

593

594

595

596

597

598

599

600

601

602

603

604

605

606

607

608

609

610

611

612

613

614

615

616

617

618

619

620

621

622

623

Graça I, Mendes VM, Marques I, Duro N, da Costa M, Ramalho JC, Pawlowski K, Manadas B, Pinto Ricardo CP, Ribeiro-Barros AI. 2019. Comparative Proteomic Analysis of Nodulated and Non-Nodulated Casuarina glauca Sieb. ex Spreng. Grown under Salinity Conditions Using Sequential Window Acquisition of All Theoretical Mass Spectra (SWATH-MS). Int J Mol Sci 21(1):78. DOI: 10.3390/ijms21010078.

Halfter U, Ishitani M, Zhu JK. 2000. The Arabidopsis SOS2 protein kinase physically interacts with and is activated by the calcium-binding protein SOS3. Proceedings of the National Academy of Sciences of the United States of America 97(7): 3735-3740 DOI: 10.1073/pnas.040577697.

Heo JO, Chang KS, Kim IA, Lee MH, Lee SA, Song SK, Lee MM, Lim J. 2011. Funneling of gibberellin signaling by the GRAS transcription regulator scarecrow-like 3 in the Arabidopsis root. Proceedings of the National Academy of Science of the United States America 108(5):2166-2171 DOI: 10.1073/pnas.1012215108

Horie T, Yoshida K, Nakayama H, Yamada K, Oiki S, Shinmyo A. 2001. Two types of HKT transporters with different properties of $\mathrm{Na}^{+}$and $\mathrm{K}^{+}$transport in Oryza sativa. The Plant Journal 27(2):129-138. DOI: 10.1046/j.1365-313x.2001.01077.x.

Horie T, Sugawara M, Okada T, Taira K, Kaothien-Nakayama P, Katsuhara M, Shinmyo A, Nakayama H. 2011. Rice sodium-insensitive potassium transporter, OsHAK5, confers increased salt tolerance in tobacco BY2 cells. J Biosci Bioeng 111(3):346-56. DOI: 10.1016/j.jbiosc.2010.10.014.

Huang L, Kuang L, Wu L, Shen Q, Zhang G. 2020. The HKT transporter HvHKT1; 5 negatively regulates salt tolerance. Plant physiology 182(1):584-596. DOI: 10.1104/pp.19.00882

Ishitani M, Liu J, Halfter U, Kim CS, Shi W, Zhu JK. 2000. SOS3 function in plant salt tolerance requires N-myristoylation and calcium binding. The Plant cell 12(9):1667-1677. DOI: $10.2307 / 3871181$

Jiang Y, Deyholos MK. 2006. Comprehensive transcriptional profiling of NaCl-stressed Arabidopsis roots reveals novel classes of responsive genes. BMC Plant Biology 6:25. DOI: $10.1186 / 1471-2229-6-25$

Jin J, Tian F, Yang DC, Meng YQ, Kong L, Luo J, Gao G. 2017. Plant-TFDB 4.0: toward a central hub for transcription factors and regulatory interactions in plants. Nucleic Acids Research 45(D1): D1040-D1045. DOI: 10.1093/nar/gkw982.

Jing L, Sebastien B, Petri T, Nina S, Hannes K, Liisa H, Tapio PE. 2013. Defense-related transcription factors WRKY70 and WRKY54 modulate osmotic stress tolerance by regulating stomatal aperture in Arabidopsis. The New phytologist 200(2):457-472. DOI: 10.1111/nph.12378.

Peer) reviewing PDF | (2021:02:58311:2:0:NEW 2 Aug 2021) 
624

625

626

627

628

629

630

631

632

633

634

635

636

637

638

639

640

641

642

643

644

645

646

647

648

649

650

651

652

653

654

655

656

657

658

Jorge TF, Tohge T, Wendenburg R, Ramalho JC, António C. 2019. Salt-stress secondary metabolite signatures involved in the ability of Casuarina glauca to mitigate oxidative stress. Environmental and Experimental Botany 166:103808. DOI: 10.1016/j.envexpbot.2019.103808.

Jorge T.F., Duro N., Costa MD, Florian A, Ramalho JC, Ribeiro-Barros AI, Fernie AR, António C. 2017. GC-TOF-MS analysis reveals salt stress-responsive primary metabolites in Casuarina glauca tissues. Metabolomics 13(8):95. DOI: 10.1007/s11306-017-1234-7.

Kacprzyk J, Daly CT, Mccabe PF. 2011. The botanical dance of death: programmed cell death in plants. Advances in botanical research 60:169-261. DOI: 10.1016/b978-0-12-3858511.00004-4.

Kawasaki S, Borchert C, Deyholos M, Wang H, Brazille S, Kawai K, Galbraith D, Bohnert HJ. 2001. Gene expression profiles during the initial phase of salt stress in rice. The Plant Cell 13:889-905. DOI: 10.1105/tpc.13.4.889.

Laloi C, Apel K, Danon A. 2004. Reactive oxygen signaling: the latest news. Current Opinon in Plant Biology 7(3):323-328. DOI: 10.1016/j.pbi.2004.03.005

Lin JS, Wang Y, Wang GX. 2006. Salt stress-induced programmed cell death in tobacco protoplasts is mediated by reactive oxygen species and mitochondrial permeability transition pore status. Journal of plant physiology 163(7): 731-739. DOI: 10.1016/j.jplph.2005.06.016

Liu SH, Fu BY, Xu HX, Zhu LH, Zhai HQ, Li ZK. 2006. Cell death in response to osmotic and salt stresses in two rice (Oryza sativa L.) ecotypes. Plant Science 172(5): 897-902. DOI: 10.1016/j.plantsci.2006.12.017.

Liu JG, Han X, Yang T, Cui WH, Wu AM, Fu CX, Wang BC, Liu LJ. 2019. Genome-wide transcriptional adaptation to salt stress in Populus. BMC Plant Biol 19(1):367. DOI: 10.1186/s12870-019-1952-2.

Lopes FES, da Costa HPS, Souza PFN, Oliveira JPB, Ramos MV, Freire JEC, Jucá TL, Freitas CDT. 2019. Peptide from thaumatin plant protein exhibits selective anticandidal activity by inducing apoptosis via membrane receptor. Phytochemistry 159:46-55. DOI: 10.1016/j.phytochem.2018.12.006.

Mansour SR, Abdel-Lateif K, D Bogusz, Franche C. 2016. Influence of salt stress on inoculated Casuarina glauca seedlings. Symbiosis 70(1-3):129-138. DOI: 10.1007/s13199-0160425-8.

Miller G, Suzuki N, Ciftci-Yilmaz S, Mittler R. 2010. Reactive oxygen species homeostasis and signalling during drought and salinity stresses. Plant, cell \& environment 33(4):453467. DOI: 10.1111/j.1365-3040.2009.02041.x.

Peer] reviewing PDF | (2021:02:58311:2:0:NEW 2 Aug 2021) 
659

660

661

662

663

664

665

666

667

668

669

670

671

672

673

674

675

676

677

678

679

680

681

682

683

684

685

686

687

688

689

690

691

692

693

694

Morton MJL, Awlia M, Al-Tamimi N, Saade S, Pailles Y, Negrão S, Tester M. 2019. Salt stress under the scalpel - dissecting the genetics of salt tolerance. Plant J 97(1):148-163. DOI: $10.1111 /$ tpj.14189.

Munns R. 2002. Comparative physiology of salt and water stress. Plant cell and environment. 25: 239-250. DOI: 10.1046/j.0016-8025.2001.00808.x

Ngom M, Gray K, Diagne N, Oshone R, Fardoux J, Gherbi H, Hocher V, Svistoonoff S, Laplaze L, Tisa LS, Sy MO, Champion A. 2016. Symbiotic Performance of Diverse Frankia Strains on Salt-Stressed Casuarina glauca and Casuarina equisetifolia Plants. Front Plant Sci 7:1331. DOI: 10.3389/fpls.2016.01331.

Park HJ, Kim WY, Yun DJ. 2016. A New Insight of Salt Stress Signaling in Plant. Mol Cells 39(6):447-59. DOI: 10.14348/molcells.2016.0083.

Passioura JB, Munns R. 2000. Rapid environmental changes that affect leaf water status induce transient surges and pauses in leaf expansion rate. Functional plant biology 27: 941948. DOI: 10.1071/PP99207.

Petrov V, Hille J, Mueller-Roeber B, Gechev TS. 2015. ROS-mediated abiotic stress-induced programmed cell death in plants. Frontiers in Plant Science 6:69 DOI :10.3389/fpls.2015.00069.

Qiu QS, Guo Y, Dietrich MA, Schumaker KS, Zhu JK. 2002. Regulation of SOS1, a plasma membrane $\mathrm{Na}^{+} / \mathrm{H}^{+}$exchanger in Arabidopsis thaliana, by SOS2 and SOS3. Proceedings of the National Academy of Sciences of the United States of America 99(12): 8436-8441. DOI: 10.1073/pnas.122224699.

Schmittgen TD, Livak KJ. 2008. Analyzing real-time PCR data by the comparative C(T) method. Nature protocols 3(6):1101-1108. DOI: 10.1038/nprot.2008.73

Scotti-Campos P, Duro N, Costa Md, Pais IP, Rodrigues AP, Batista-Santos P, Semedo JN, Leitão AE, Lidon FC, Pawlowski K, Ramalho JC, Ribeiro-Barros AI. 2016. Antioxidative ability and membrane integrity in salt-induced responses of Casuarina glauca Sieber ex Spreng. in symbiosis with N2-fixing Frankia Thr or supplemented with mineral nitrogen. J Plant Physiol 196-197:60-9. DOI: 10.1016/j.jplph.2016.03.012.

Selvakesavan RK, Dhanya NN, Thushara P, Abraham SM, Jayaraj RSC, Balasubramanian A, Deeparaj B, Sudha S, Rani KSS, Bachpai VKW. 2016. Intraspecies variation in sodium partitioning, potassium and proline accumulation under salt stress in Casuarina equisetifolia Forst. Symbiosis 70(1-3):117-127. DOI: 10.1007/s13199-016-0424-9.

Shao J, Markham J, Renault S. 2020. Nitrogen fixation symbiosis and salt tolerance of the boreal woody species Elaeagnus commutata. Acta Physiologiae Plantarum 42(6):1-9. DOI: 10.1007/s11738-020-03088-y.

Peer) reviewing PDF | (2021:02:58311:2:0:NEW 2 Aug 2021) 
695

696

697

698

699

700

701

702

703

704

705

706

707

708

709

710

711

712

713

714

715

716

717

718

719

720

721

722

723

724

725

726

727

728

729

730

Sun WB, Zhou Y, Movahedi A, Wei H, Zhuge Q. 2020. Thaumatin-like protein(Pe-TLP)acts as a positive factor in transgenic poplars enhanced resistance to spots disease. Physiol Mol Plant Pathol 112: 101512. DOI: 10.1016/j.pmpp.2020.101512.

Suzuki N, Koussevitzky S, Mittler RON, Miller GAD. 2012. ROS and redox signalling in the response of plants to abiotic stress. Plant, Cell \& Environment 35(2):259-270. DOI: 10.1111/j.1365-3040.2011.02336.x.

Tani C, Sasakawa H. 2003. Salt tolerance of Casuarina equisetifolia and Frankia Ceq1 strain isolated from the root nodules of C. equisetifolia. Soil Science and Plant Nutrition 49(2):215-222. DOI: 10.1080/00380768.2003.10410000.

Tani C, Sasakawa H. 2010. Proline accumulates in Casuarina equisetifolia seedlings under salt stress. Soil Science \& Plant Nutrition 52(1):21-25. DOI: 10.1111/j.17470765.2006.00005.x

Tu Y, Jiang A, Gan L, Hossain M, Zhang J, Peng B, Xiong Y, Song Z, Cai D, Xu W, Zhang J, He Y. 2014. Genome duplication improves rice root resistance to salt stress. Rice 7(1):1-13. DOI:10.1186/s12284-014-0015-4.

Van Zelm E, Zhang Y, Testerink C. 2020. Salt Tolerance Mechanisms of Plants. Annu Rev Plant Biol 71:403-433. DOI: 10.1146/annurev-arplant-050718-100005.

Wang L, Liu YH, Feng SJ, Wang ZY, Zhang JW, Zhang JL, Wang D, Gan YT. 2018. AtHKT1 gene regulating $\mathrm{K}^{+}$state in whole plant improves salt tolerance in transgenic tobacco plants. Scientific Reports 8(1):16585. DOI: 10.1038/s41598-018-34660-9.

Weinl S, Kudla J. 2009. The CBL-CIPK Ca ${ }^{2+}$-decoding signaling network: function and perspectives. New Phytol 184(3):517-528. DOI: 10.1111/j.1469-8137.2009.02938.x.

Wu C, Zhang Y, Tang SM, Zhong CL. 2010. Effect of NaCl Stress on Casuarina Seed Germination. Seed 29 (4):30-33. DOI: 10.3724/SP.J.1011.2010.01267.

Xie M, Sun J, Gong D, Kong Y. 2019. The Roles of Arabidopsis C1-2i Subclass of C2H2-type Zinc-Finger Transcription Factors. Genes 10(9):653. DOI: 10.3390/genes10090653.

Yang T, Zhang S, Hu Y. 2014. The role of a potassium transporter OsHAK5 in potassium acquisition and transport from roots to shoots in rice at low potassium supply levels. Plant Physiology 166(2): 945-959. DOI: 10.1104/pp.114.246520.

Yang O, Popova OV, Süthoff U, Lüking I, Dietz KJ, Golldack D. 2009. The Arabidopsis basic leucine zipper transcription factor AtbZIP24 regulates complex transcriptional networks involved in abiotic stress resistance. Gene 436 (1):0-55. DOI: 10.1016/j.gene.2009.02.010.

Ye G, Zhang H, Chen B, Nie S, Liu H, Gao W, Wang H, Gao Y, Gu L. 2019. De novo genome assembly of the stress tolerant forest species Casuarina equisetifolia provides insight into secondary growth. The Plant Journal 97(4):779-794. DOI: 10.1111/tpj.14159.

Peer] reviewing PDF | (2021:02:58311:2:0:NEW 2 Aug 2021) 
731 Yu G, Rui W, Wei WC, Fei X, Xueliang W, Yeen CPM, Cliff T, Lina D, R DJ. 2013. A spatio-

732

733

734

735

736

737

738

739

740

741

742

743

744

745

746

747

748 temporal understanding of growth regulation during the salt stress response in Arabidopsis. The Plant cell 25(6):2132-2154 DOI:10.1105/tpc.113.112896.

Yu Z, Duan X, Luo L, Dai S, Ding Z, Xia G. How Plant Hormones Mediate Salt Stress Responses. 2020. Trends Plant Sci 25(11):1117-1130. DOI: 10.1016/j.tplants.2020.06.008.

Zhang H, Xiao W, Yu W, Jiang Y, Li R. 2020. Halophytic Hordeum brevisubulatum HbHAK1 Facilitates Potassium Retention and Contributes to Salt Tolerance. Int J Mol Sci 21(15):5292. DOI: 10.3390/ijms21155292.

Zhong C, Shi C, Wang W, Bai J, Jin SU, KPinyopusarerk. 2001. Provenance Trials of Casuarina equisetifolia in Southern China. Forest Research 4:408-415.

Zhong C, Zhang Y, Chen Y, Jiang Q, Chen Z, Liang J, Pinyopusarerk K, Franche C, Bogusz D. 2010. Casuarina research and applications in China. Symbiosis 50(1-2):107-114. DOI: 10.1007/s13199-009-0039-5.

Zhu JK. 2003. Regulation of ion homeostasis under salt stress. Current opinion in plant biology 6 (5): 441-445. DOI: 10.1016/S1369-5266(03)00085-2. 
749

750

751

752

753

754

755

756

757

758

759

760

761

762

763

764

765

766

767

768

769

770

771

772

773

774

775

776

777

778

779

780

\section{FIGURES}

Fig. 1 Morphological changes in roots of $\boldsymbol{C}$. equisetifolia under salt stress. The seedlings were treated by $200 \mathrm{mM} \mathrm{NaCl}$ solution for $0,1,6,24$, and $168 \mathrm{~h}$. Root analysis was performed in C. equisetifolia in response to salt stress. The white arrows indicate new roots, and the white boxes indicate dead roots.

Fig. 2 Microstructure changes in roots of $C$. equisetifolia under salt stress. After treatment with $200 \mathrm{mM} \mathrm{NaCl}$ solution for $0,1,6,24$ and $168 \mathrm{~h}$, roots were collected for microstructure analysis. Ep, Epidermis; Ex, Exodermis; En, Endodermis; St, Stele.

Fig. 3 Ultrastructure of epidermis change in root cells of $C$. equisetifolia under salt stress. Root analysis was performed in response to salt stress by $200 \mathrm{mM} \mathrm{NaCl}$ solution for $0,1,6,24$, and $168 \mathrm{~h}$. The first line of the picture: the changes of the local epidermis at different time periods under salt treatment. The second line of the picture: individual epidermal cells treated by salt at different times. The third row of the picture: the number of mitochondria in a single epidermal cell during different time periods under salt treatment. The fourth row of the picture: the changes of mitochondrial structure in a single epidermal cell during different time periods under salt treatment. $\mathrm{CW}$, cell wall; $\mathrm{M}$, mitochondria.

Fig. 4 Ultrastructure of cortex change in root cells of $\boldsymbol{C}$. equisetifolia under salt stress. Root analysis was performed in response to salt stress by $200 \mathrm{mM} \mathrm{NaCl}$ solution for $0,1,6,24$, and $168 \mathrm{~h}$. The first line of the picture: the changes of the local cortex at different time periods under salt treatment. The second line of the picture: individual cortical cells treated by salt at different times. The third row of the picture: the number of mitochondria in a single cortical cell during different time periods under salt treatment. The fourth row of the picture: the changes of mitochondrial structure in a single cortical cell during different time periods under salt treatment. $\mathrm{CW}$, cell wall; $\mathrm{M}$, mitochondria.

Fig. 5 Ultrastructure of stele change in root cells of $\boldsymbol{C}$. equisetifolia under salt stress. Root analysis was performed in response to salt stress by $200 \mathrm{mM} \mathrm{NaCl}$ solution for $0,1,6,24$, and $168 \mathrm{~h}$. The first line of the picture: the changes of the local stele at different time periods under salt treatment. The second line of the picture: individual stele cells treated by salt at different times. The third row of the picture: the number of mitochondria in a single stele cell during different time periods under salt treatment. The fourth row of the picture: the changes of mitochondrial structure in a single stele cell during different time periods under salt treatment. $\mathrm{CW}$, cell wall; M, mitochondria; Pe, pericycle; Ve, vesicle; V, vacuole. 
781

782

783

784

785

786

787

788

789

790

791

792

793

794

795

796

797

798

799

800

801

802

Fig. 6. DEGs analysis at different time points under salt stress. Venn diagram showing the number of DEGs in C. equisetifolia at 1, 6, 24, and $168 \mathrm{~h}$ of exposure to $200 \mathrm{mM} \mathrm{NaCl}$ solution. The column diagram indicated the number of up-regulated and down-regulated DEGs. The table showed the DEGs between the two samples.

Fig. 7 GO enrichment analysis at different time points under salt stress. The biological processes analysis of differentially expressed genes (DEGs). Log10 was applied to the number of enriched DEGs. The darker the color, the more DEGs are enriched.

Fig. 8 DEGs at different time points under salt stress. (A) Expression profiles of all DEGs at different time points under salt stress. Log10 was performed on the TPM value. The color scale on the right side represents values of normalized TPM values. Blue represents low expression and red indicates a high expression level. The heatmap was constructed by $\mathrm{R}$ package (Pheatmap). (B) The distribution of representative 689 TFs. Different colors represent different TFs.

\section{Fig. 9 Expression profiles of DEGs related to ion transport and PCD-related genes at} different time points under salt stress. (A) Expression pattern of 26 DEGs related to ion transport. The color scale on the right side represents values of normalized TPM values. Blue represents low expression and red indicates a high expression level. The heatmap was constructed by $R$ package (Pheatmap). (B) Expression profiles of PCD-related genes. The color scale on the right side represents values of normalized TPM values. Blue represents low expression and red indicates a high expression level. The heatmap was constructed by R package (Pheatmap).

PeerJ reviewing PDF | (2021:02:58311:2:0:NEW 2 Aug 2021) 
804 TABLES

805 Table 1 Ions content changed in $C$. equisetifolia root under salt stress. $\mathrm{Na}^{+}, \mathrm{Cl}^{-}$and $\mathrm{K}^{+}$ 806 content was measured in roots under $200 \mathrm{mM} \mathrm{NaCl}$ treatment for $0,1,6,24$, and $168 \mathrm{~h}$. The 807 average values and standard deviations (SDs) were obtained from three replicates, and the data 808 were analyzed using one-way ANOVA: the software employed was IBM SPSS Statistics ver. 19 809 for Windows.

810

811

812

813

814

815

816

817

818

819

820

821

822

823

824

825

826

827

828

\section{SUPPORTING INFORMATION}

Fig. S1. The scatter-plot analysis of samples with two biological replicates (rep_1 and rep_2). (A) All samples were clustered. (B) Pair-wise Pearson's correlations of expression values between biological replicates. (C) The correlation of expression values between the treatment and control samples.

Fig. S2. The expression pattern of some DEGs and validation of RNA-seq data. Left panel: The relative expression levels of target genes from qRT-PCR results, and TPM values were acquired by RNA-seq. Right panel: Expression profiles of some DEGs, and the heatmap was constructed by R package (Pheatmap).

\section{Table S1 Primers used for qRT-PCR of genes in C. equisetifolia.}

Table S2 Mapping rate of clean reads to the reference genome.

Table S3 Summary of the DEGs. The total differentially expressed genes in Table S3-1. The DEGs of 1, 6, 24, and $168 \mathrm{~h}$ vs control are detailed in Table S3-2 to Table S3-5. The DEGs of different salt treatment are detailed in Table S3-6 to Table S3-11.

Table S4 Gene ontology of the DEGs. Gene ontology of total DEGs in Table S4-1. Gene ontology analysis at each of the time points are detailed in Table S4-2 to Table S4-5.

\section{Table S5 The TPM values of the total DEGs.}

Table S6 The DEGs encoding TFs under salt stress in C. equisetifolia. 


\section{Figure 1}

Morphological changes in roots of $C$. equisetifolia under salt stress.

The seedlings were treated by $200 \mathrm{mM} \mathrm{NaCl}$ solution for $0,1,6,24$, and $168 \mathrm{~h}$. Root analysis was performed in $C$. equisetifolia in response to salt stress. The white arrows indicate new roots, and the white boxes indicate dead roots. 
Control

$1 \mathrm{H}$

$6 \mathrm{H}$

$24 \mathrm{H}$

$168 \mathrm{H}$

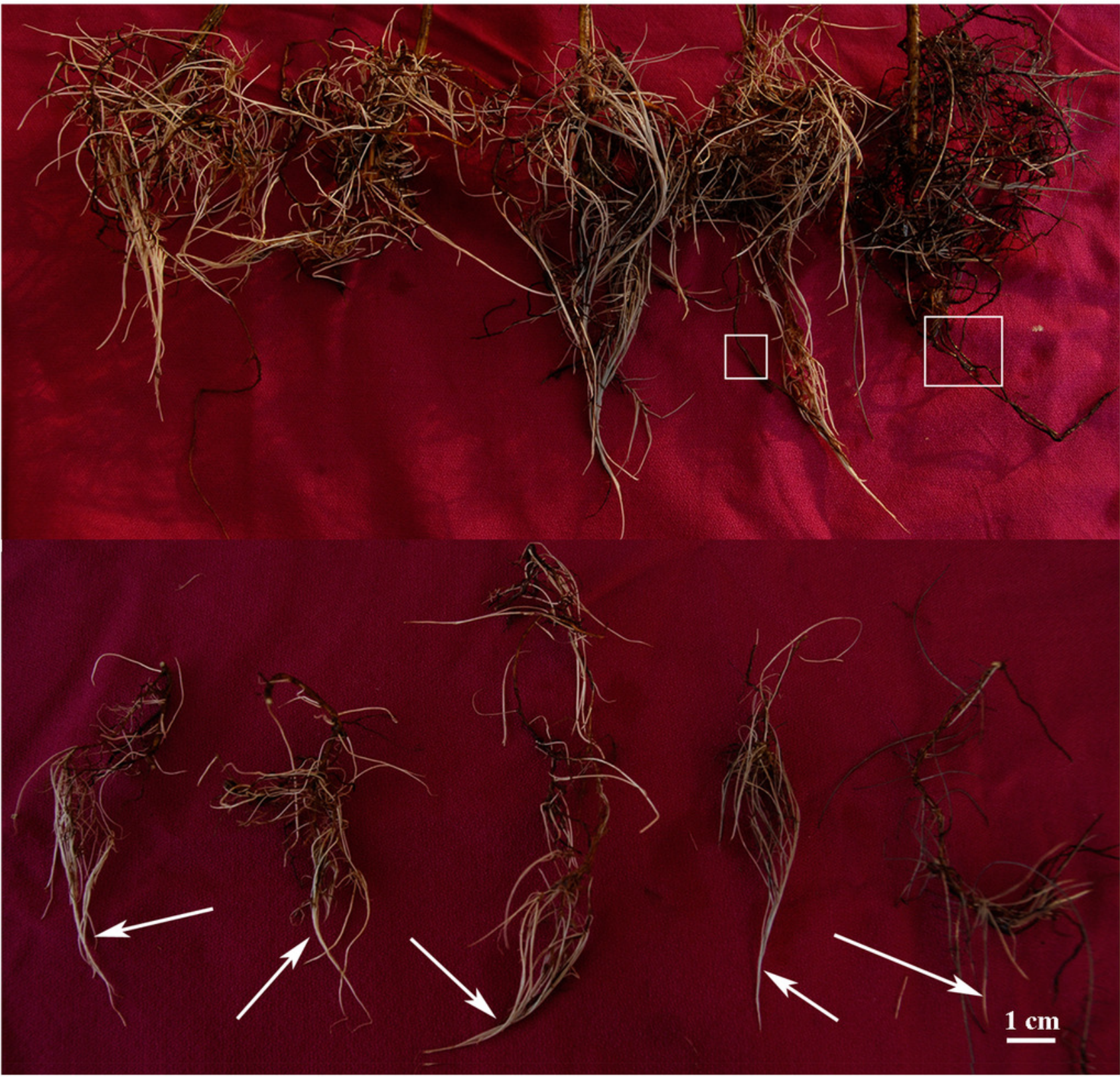




\section{Figure 2}

Microstructure changes in roots of $C$. equisetifolia under salt stress.

After treatment with $200 \mathrm{mM} \mathrm{NaCl}$ solution for $0,1,6,24$ and $168 \mathrm{~h}$, roots were collected for microstructure analysis. Ep, Epidermis; Ex, Exodermis; En, Endodermis; St, Stele.
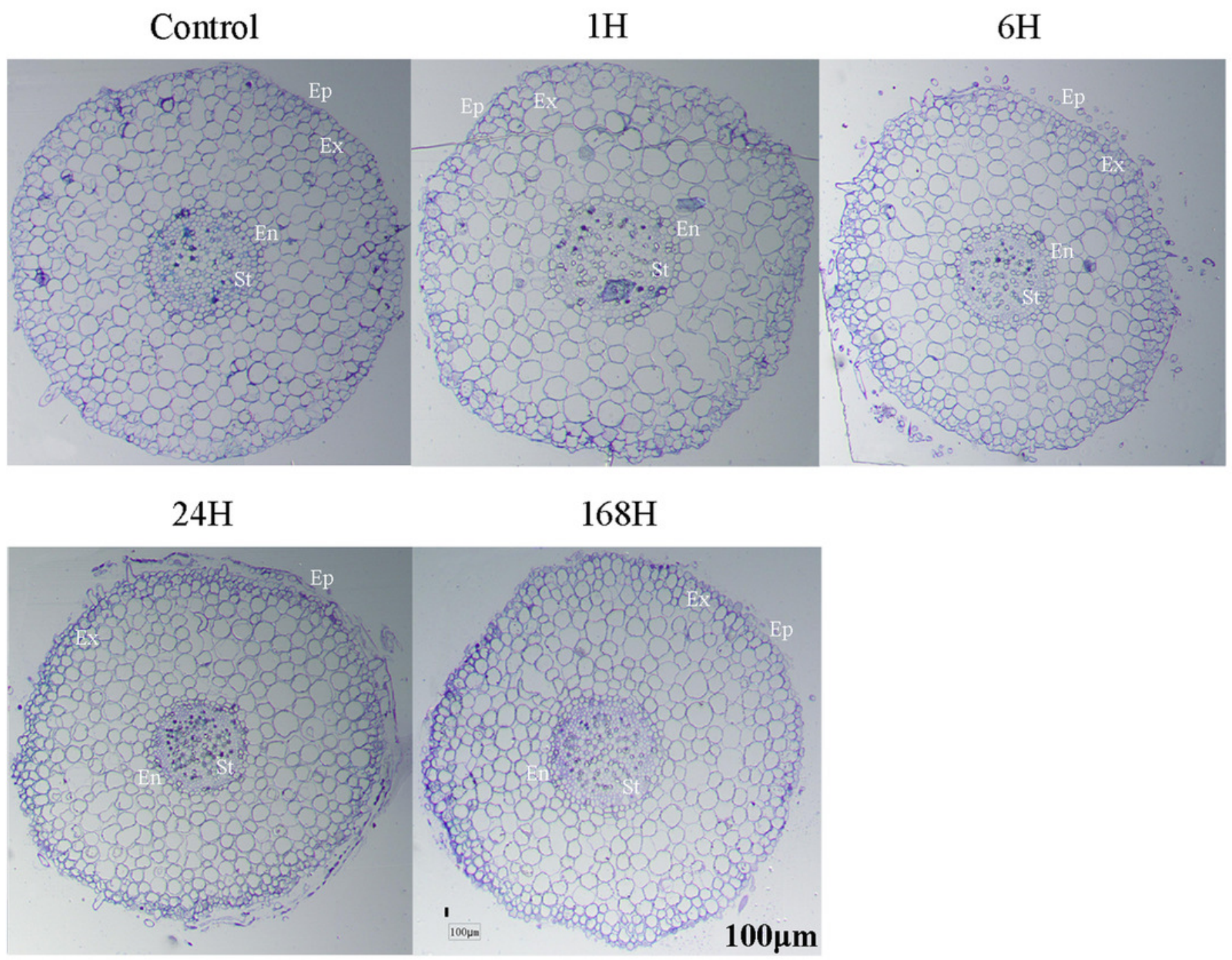


\section{Figure 3}

Ultrastructure of epidermis change in root cells of $C$. equisetifolia under salt stress.

Root analysis was performed in response to salt stress by $200 \mathrm{mM} \mathrm{NaCl}$ solution for $0,1,6$, 24 , and $168 \mathrm{~h}$. The first line of the picture: the changes of the local epidermis at different time periods under salt treatment. The second line of the picture: individual epidermal cells treated by salt at different times. The third row of the picture: the number of mitochondria in a single epidermal cell during different time periods under salt treatment. The fourth row of the picture: the changes of mitochondrial structure in a single epidermal cell during different time periods under salt treatment. CW, cell wall; $\mathrm{M}$, mitochondria. 


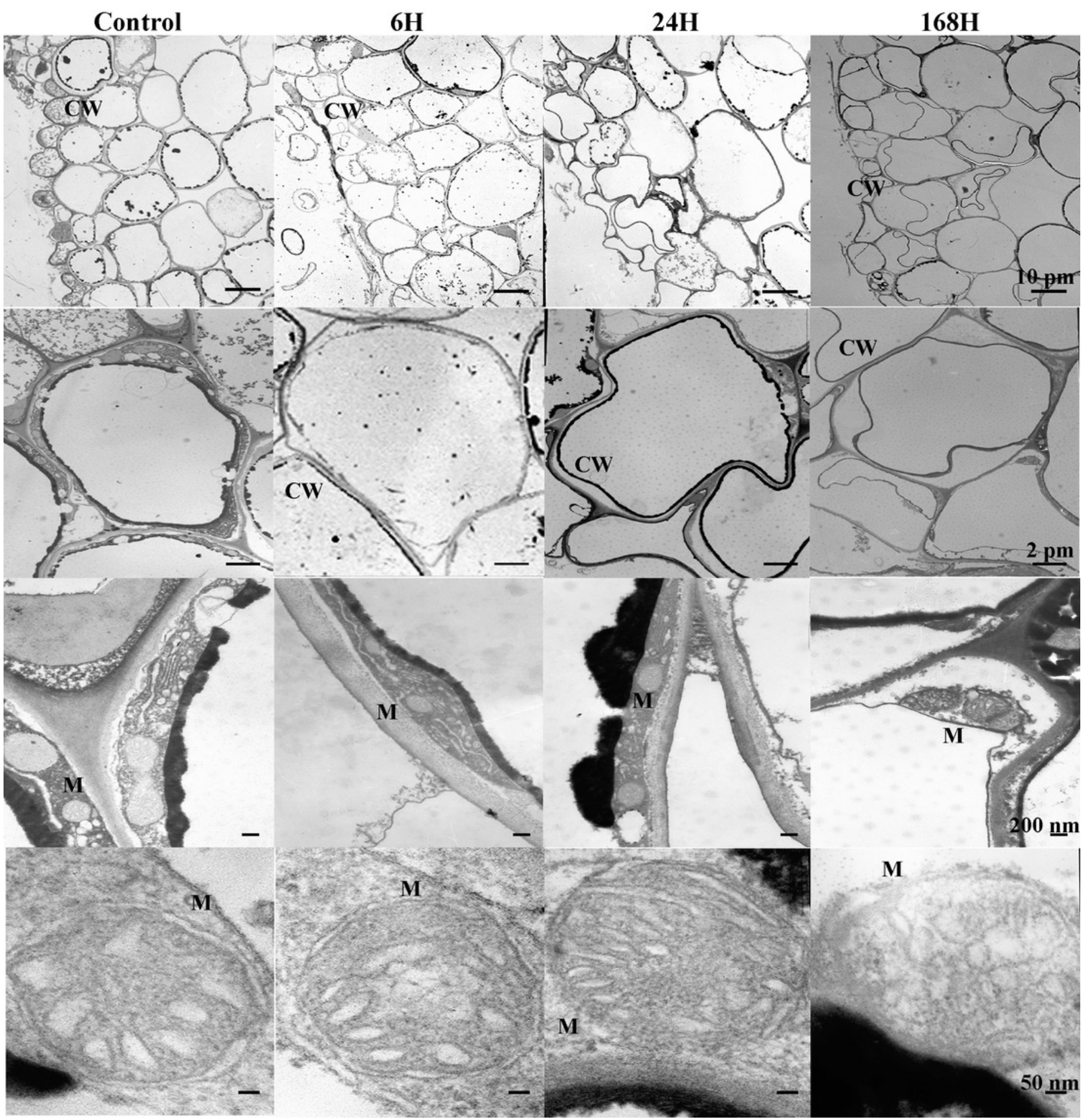




\section{Figure 4}

Ultrastructure of cortex change in root cells of $C$. equisetifolia under salt stress.

Root analysis was performed in response to salt stress by $200 \mathrm{mM} \mathrm{NaCl}$ solution for $0,1,6$, 24 , and $168 \mathrm{~h}$. The first line of the picture: the changes of the local cortex at different time periods under salt treatment. The second line of the picture: individual cortical cells treated by salt at different times. The third row of the picture: the number of mitochondria in a single cortical cell during different time periods under salt treatment. The fourth row of the picture: the changes of mitochondrial structure in a single cortical cell during different time periods under salt treatment. CW, cell wall; M, mitochondria. 


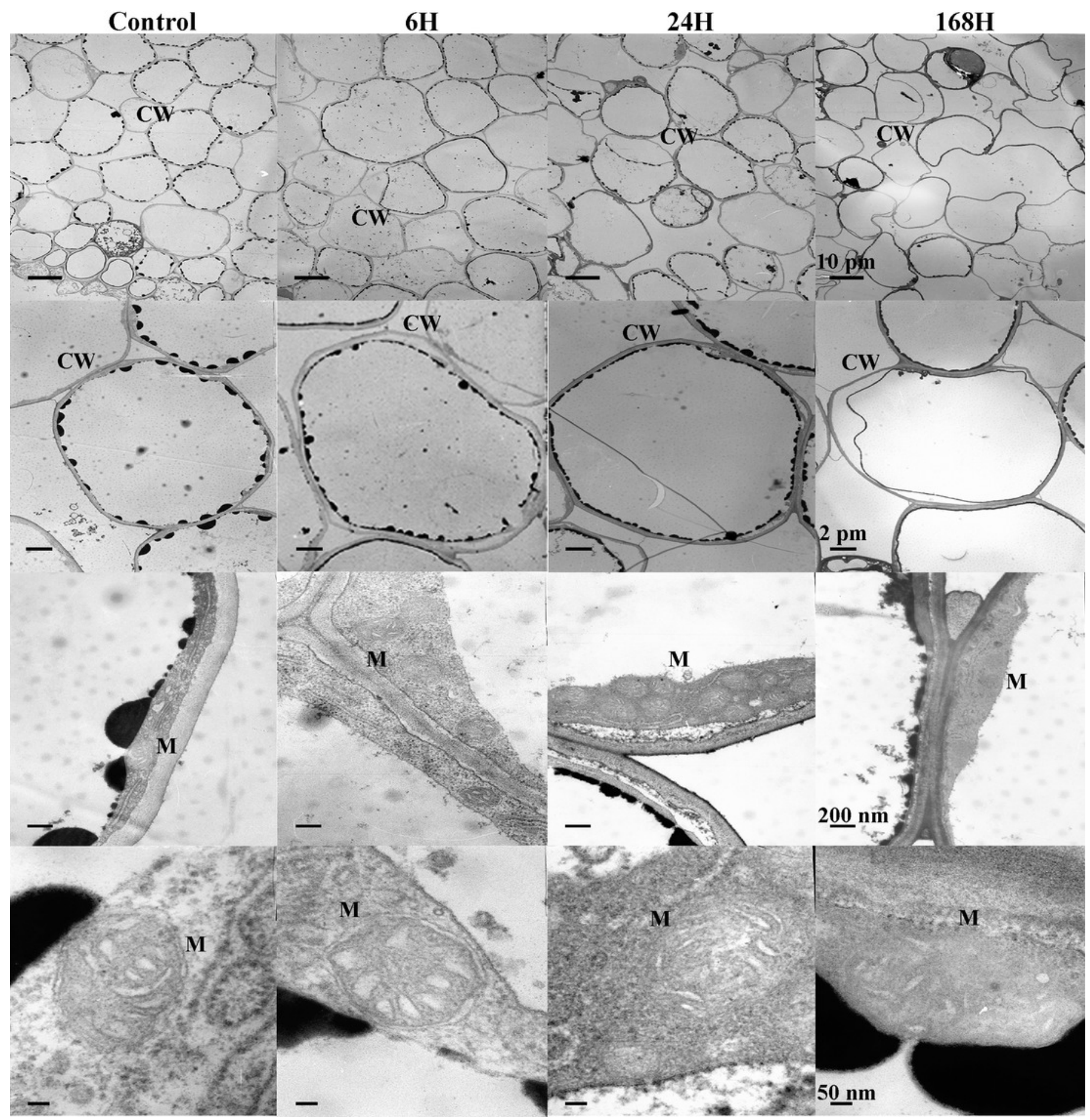




\section{Figure 5}

Ultrastructure of stele change in root cells of $C$. equisetifolia under salt stress.

Root analysis was performed in response to salt stress by $200 \mathrm{mM} \mathrm{NaCl}$ solution for $0,1,6$, 24 , and $168 \mathrm{~h}$. The first line of the picture: the changes of the local stele at different time periods under salt treatment. The second line of the picture: individual stele cells treated by salt at different times. The third row of the picture: the number of mitochondria in a single stele cell during different time periods under salt treatment. The fourth row of the picture: the changes of mitochondrial structure in a single stele cell during different time periods under salt treatment. CW, cell wall; M, mitochondria; Pe, pericycle; Ve, vesicle; V, vacuole. 


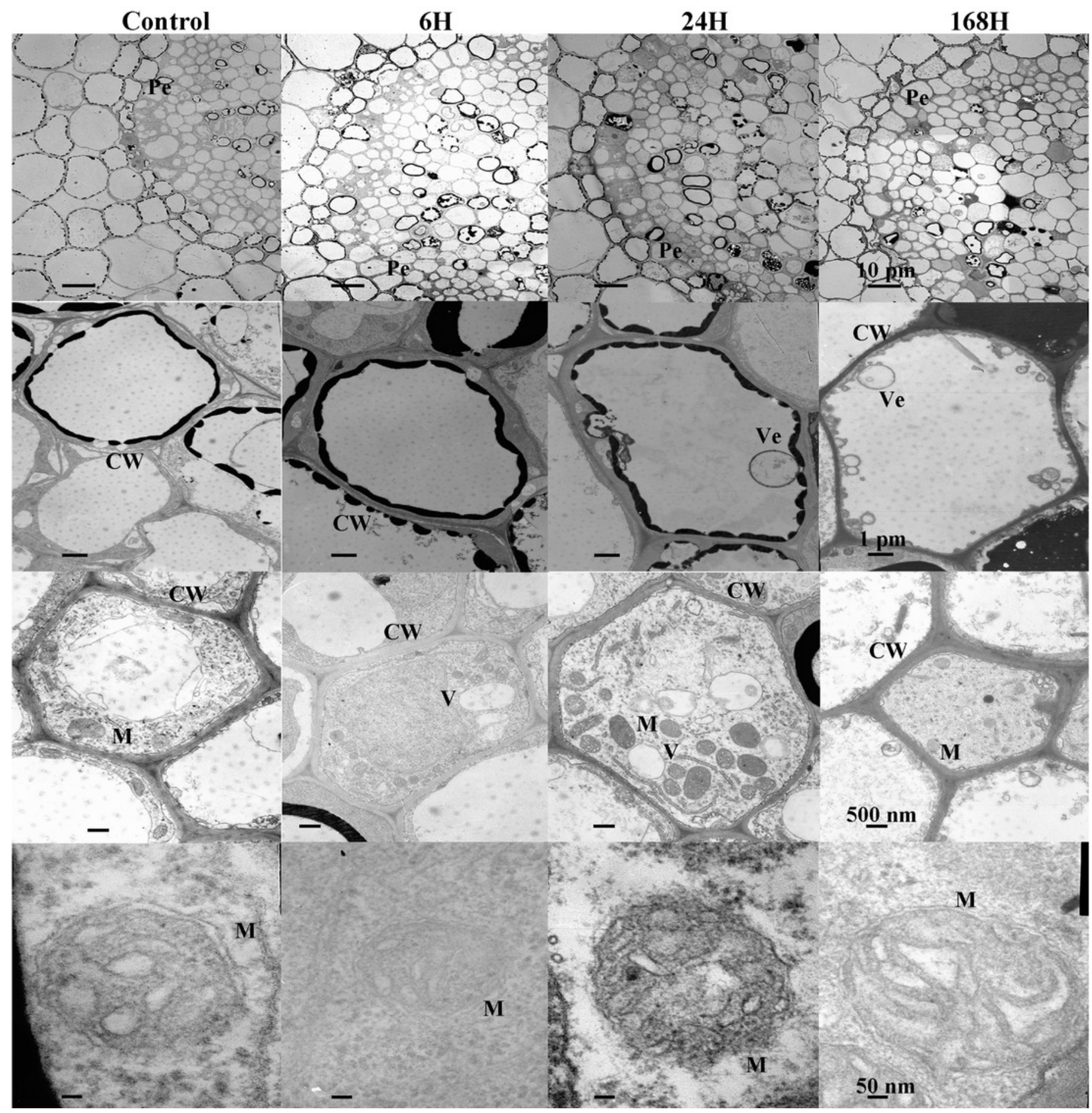


Figure 6

DEGs analysis at different time points under salt stress.

Venn diagram showing the number of DEGs in C. equisetifolia at 1, 6, 24, and $168 \mathrm{~h}$ of exposure to $200 \mathrm{mM} \mathrm{NaCl}$ solution. The column diagram indicated the number of upregulated and down-regulated DEGs. The table showed the DEGs between the two samples.

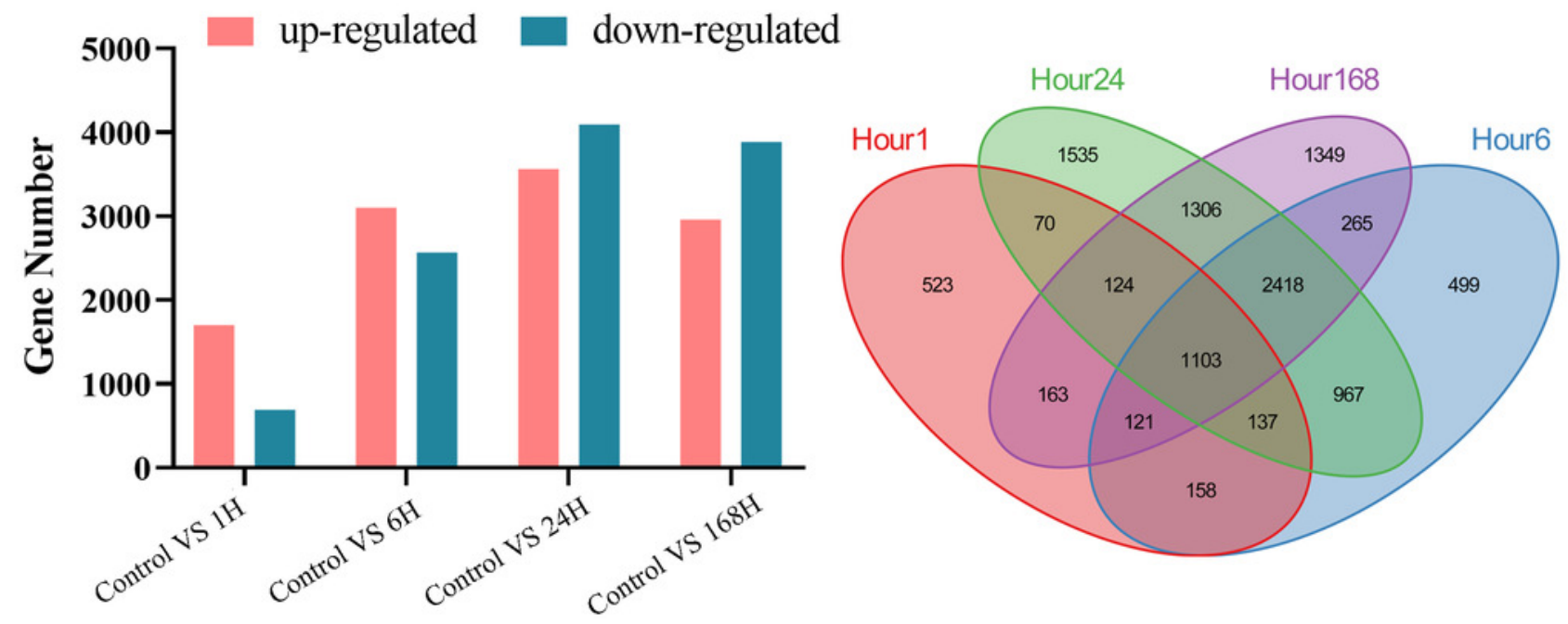

\begin{tabular}{|c|c|c|c|c|c|c|c|c|c|c|}
\hline Category & CK vs $1 \mathrm{~h}$ & CK vs $6 \mathrm{~h}$ & CK vs $24 \mathrm{~h}$ & CK vs $168 \mathrm{~h}$ & $1 \mathrm{~h}$ vs $6 \mathrm{~h}$ & $1 \mathrm{~h}$ vs $24 \mathrm{~h}$ & $1 \mathrm{~h}$ vs $168 \mathrm{~h}$ & $6 \mathrm{~h}$ vs $24 \mathrm{~h}$ & $6 \mathrm{~h}$ vs $168 \mathrm{~h}$ & $24 \mathrm{~h}$ vs $168 \mathrm{~h}$ \\
\hline Up-regulated & 1704 & 3101 & 3565 & 2962 & 2477 & 3301 & 2590 & 1881 & 2818 & 2223 \\
\hline Down-regulated & 695 & 2567 & 4095 & 3887 & 2311 & 4288 & 3979 & 889 & 1727 & 2015 \\
\hline Total & 2399 & 5668 & 7660 & 6849 & 4788 & 7589 & 6569 & 2770 & 4545 & 4238 \\
\hline
\end{tabular}


Figure 7

GO enrichment analysis at different time points under salt stress.

The biological processes analysis of differentially expressed genes (DEGs). Log10 was applied to the number of enriched DEGs. The darker the color, the more DEGs are enriched. 


\begin{tabular}{|c|c|c|c|c|c|}
\hline $\mathrm{GO}$ & GO term & \multicolumn{4}{|c|}{ GO enrichment } \\
\hline Signal & & $1 \mathrm{~h}$ & $6 \mathrm{~h}$ & $24 \mathrm{~h}$ & $168 \mathrm{~h}$ \\
\hline \multirow{4}{*}{$\begin{array}{l}\text { GO: } 0007154 \\
\text { GO:0009966 } \\
\text { GO:0009967 } \\
\text { GO:0007166 } \\
\end{array}$} & \multirow{4}{*}{$\begin{array}{l}\text { cell communication } \\
\text { regulation of signal transduction } \\
\text { positive regulation of signal transduction } \\
\text { cell surface receptor signaling pathway }\end{array}$} & 2.33646 & & & \\
\hline & & 1.70757 & 1.9345 & & \\
\hline & & 1.579784 & 1.7634 & 1.86332 & \\
\hline & & 1.544068 & 1.8865 & 2.04532 & 2.025306 \\
\hline \multicolumn{6}{|l|}{ Hormone } \\
\hline \multirow{10}{*}{$\begin{array}{l}\text { GO:0009737 } \\
\text { GO:0009694 } \\
\text { GO:0009695 } \\
\text { GO:0009867 } \\
\text { GO:0009734 } \\
\text { GO:0010928 } \\
\text { GO:0009733 } \\
\text { GO:0009739 } \\
\text { GO:0009696 } \\
\text { GO:0010337 } \\
\end{array}$} & \multirow{10}{*}{$\begin{array}{c}\text { response to abscisic acid } \\
\text { jasmonic acid metabolic process } \\
\text { jasmonic acid biosynthetic process } \\
\text { jasmonic acid mediated signaling pathway } \\
\text { auxin-activated signaling pathway } \\
\text { regulation of auxin mediated signaling pathway } \\
\text { response to auxin } \\
\text { response to gibberellin } \\
\text { salicylic acid metabolic process } \\
\text { regulation of salicylic acid metabolic process }\end{array}$} & 1.477121 & & & \\
\hline & & 0.778151 & 0.9542 & & \\
\hline & & 0.69897 & 0.9542 & & \\
\hline & & & 1.1139 & & 1.20412 \\
\hline & & & 1.415 & & \\
\hline & & & 0.9542 & & \\
\hline & & 1.39794 & 1.7709 & 1.87506 & \\
\hline & & & 1.3424 & 1.34242 & 1.39794 \\
\hline & & & & & 0.778151 \\
\hline & & & & & 0.778151 \\
\hline \multicolumn{6}{|l|}{ Stress response } \\
\hline \multirow{7}{*}{$\begin{array}{l}\text { GO: } 0006952 \\
\text { GO:0050896 } \\
\text { GO:0009719 } \\
\text { GO:0042493 } \\
\text { GO:0009415 } \\
\text { GO:0006979 } \\
\text { GO:0009636 } \\
\end{array}$} & \multirow{7}{*}{$\begin{array}{c}\text { defense response } \\
\text { response to stimulus } \\
\text { response to endogenous stimulus } \\
\text { response to drug } \\
\text { response to water } \\
\text { response to oxidative stress } \\
\text { response to toxic substance } \\
\end{array}$} & 1.908485 & & & \\
\hline & & 2.619093 & & & \\
\hline & & 1.919078 & 2.2041 & 2.32428 & \\
\hline & & 1.255273 & 1.5563 & 1.60206 & \\
\hline & & 1.361728 & & 1.6721 & 1.69897 \\
\hline & & 1.672098 & 1.9685 & 2.04532 & 2.033424 \\
\hline & & 1.70757 & 1.8921 & 2.02119 & 2.033424 \\
\hline \multicolumn{6}{|l|}{ Transport } \\
\hline \multirow{6}{*}{$\begin{array}{l}\text { GO:0015893 } \\
\text { GO:0006811 } \\
\text { GO:0006816 } \\
\text { GO:0030001 } \\
\text { GO:0035725 } \\
\text { GO:0006814 } \\
\end{array}$} & \multirow{6}{*}{$\begin{array}{c}\text { drug transport } \\
\text { ion transport } \\
\text { calcium ion transport } \\
\text { metal ion transport } \\
\text { sodium ion transmembrane transport } \\
\text { sodium ion transport } \\
\end{array}$} & 1.230449 & 1.5441 & 1.5682 & 1.518514 \\
\hline & & 2.029384 & 2.3579 & & 2.421604 \\
\hline & & 1 & & & \\
\hline & & & 2 & 2.12057 & 2.060698 \\
\hline & & & 1.0414 & 1.07918 & 1.079181 \\
\hline & & & 1.1139 & 1.17609 & \\
\hline
\end{tabular}

Oxidation\&Detoxification

\begin{tabular}{cc} 
GO:0098754 & detoxification \\
GO:0098869 & cellular oxidant detoxification \\
GO:0042744 & hydrogen peroxide catabolic process \\
GO:0009404 & toxin metabolic process \\
GO:0055114 & oxidation-reduction process \\
\hline
\end{tabular}

\begin{tabular}{|c|c|c|c|}
\hline 1.69897 & 1.8751 & 2.00432 & 2.012837 \\
\hline 1.69897 & 1.8692 & 1.99564 & 1.995635 \\
\hline 1.556303 & 1.7076 & 1.79239 & 1.826075 \\
\hline 1 & 1.1761 & 1.34242 & 1.39794 \\
\hline 2.465383 & 2.8698 & 2.96895 & 2.932981 \\
\hline
\end{tabular}

Development\&Growth

$\begin{array}{cc}\text { GO:0030154 } & \text { cell differentiation } \\ \text { GO:0009664 } & \text { plant-type cell wall organization } \\ \text { GO:0010026 } & \text { trichome differentiation } \\ \text { GO:0046274 } & \text { lignin catabolic process } \\ \text { GO:0042545 } & \text { cell wall modification }\end{array}$

\begin{tabular}{|l|l|l|c|}
\hline 1.690196 & 2.0453 & & 2.133539 \\
\hline & 1.4624 & 1.66276 & 1.643453 \\
\hline & & 1.57978 & 1.60206 \\
\hline & & 1.32222 & 1.342423 \\
\hline & & & 1.39794 \\
\hline
\end{tabular}

Death

$\begin{array}{cc}\text { GO:0001906 } & \text { cell killing } \\ \text { GO:0031640 } & \text { killing of cells of other organism } \\ \text { GO:0044364 } & \text { disruption of cells of other organism }\end{array}$

\begin{tabular}{|l|l|l|l|}
\hline & & 1.04139 & 1.176091 \\
\hline & & 1.04139 & 1.176091 \\
\hline & & 1.04139 & 1.176091 \\
\hline
\end{tabular}


Figure 8

DEGs at different time points under salt stress.

(A) Expression profiles of all DEGs at different time points under salt stress. Log10 was performed on the TPM value. The color scale on the right side represents values of normalized TPM values. Blue represents low expression and red indicates a high expression level. The heatmap was constructed by R package (Pheatmap). (B) The distribution of representative 689 TFs. Different colors represent different TFs. 


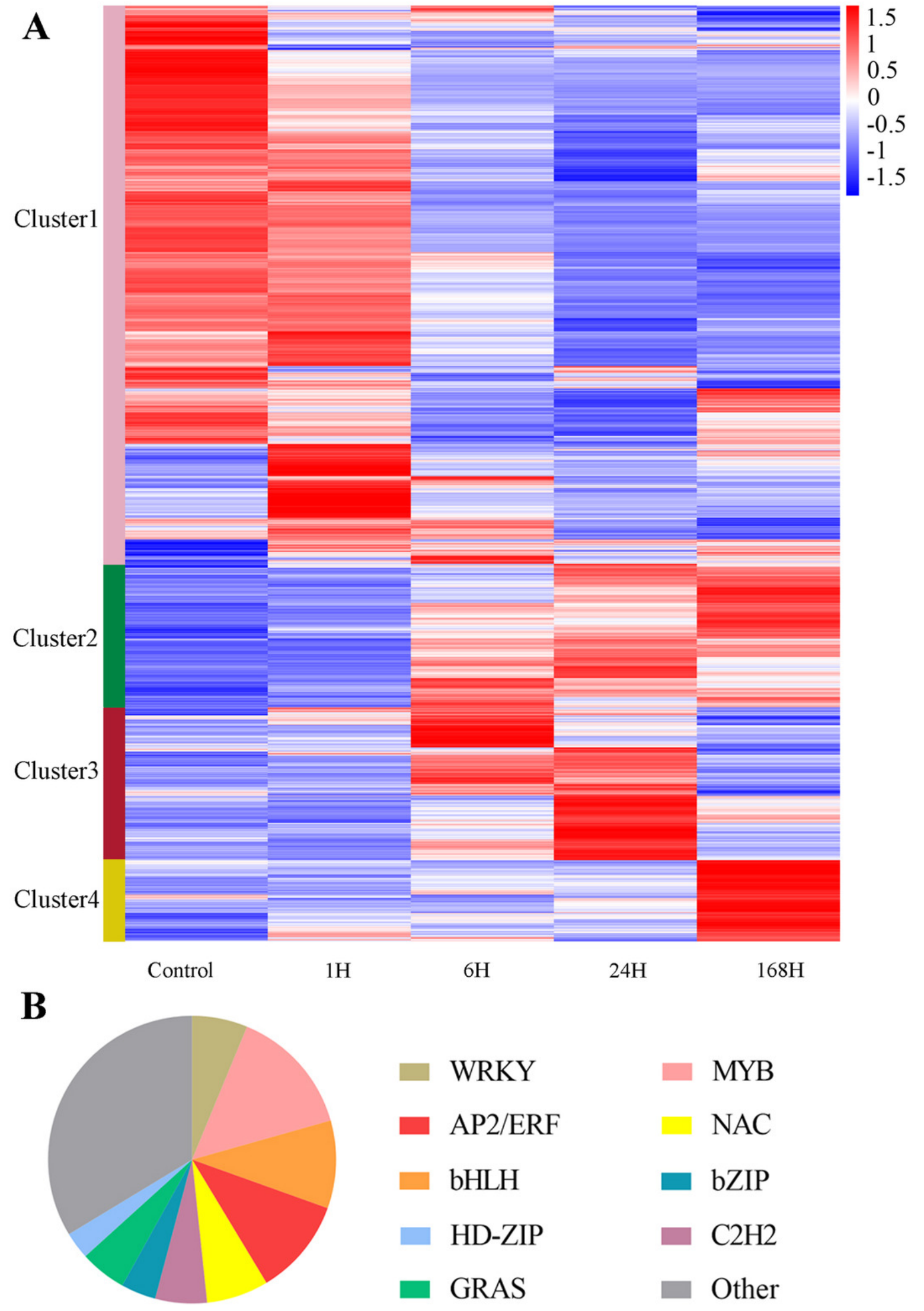

Total: 689 TFs 


\section{Figure 9}

Expression profiles of DEGs related to ion transport and PCD-related genes at different time points under salt stress.

(A) Expression pattern of 26 DEGs related to ion transport. The color scale on the right side represents values of normalized TPM values. Blue represents low expression and red indicates a high expression level. The heatmap was constructed by $R$ package (Pheatmap). (B) Expression profiles of PCD-related genes. The color scale on the right side represents values of normalized TPM values. Blue represents low expression and red indicates a high expression level. The heatmap was constructed by R package (Pheatmap).

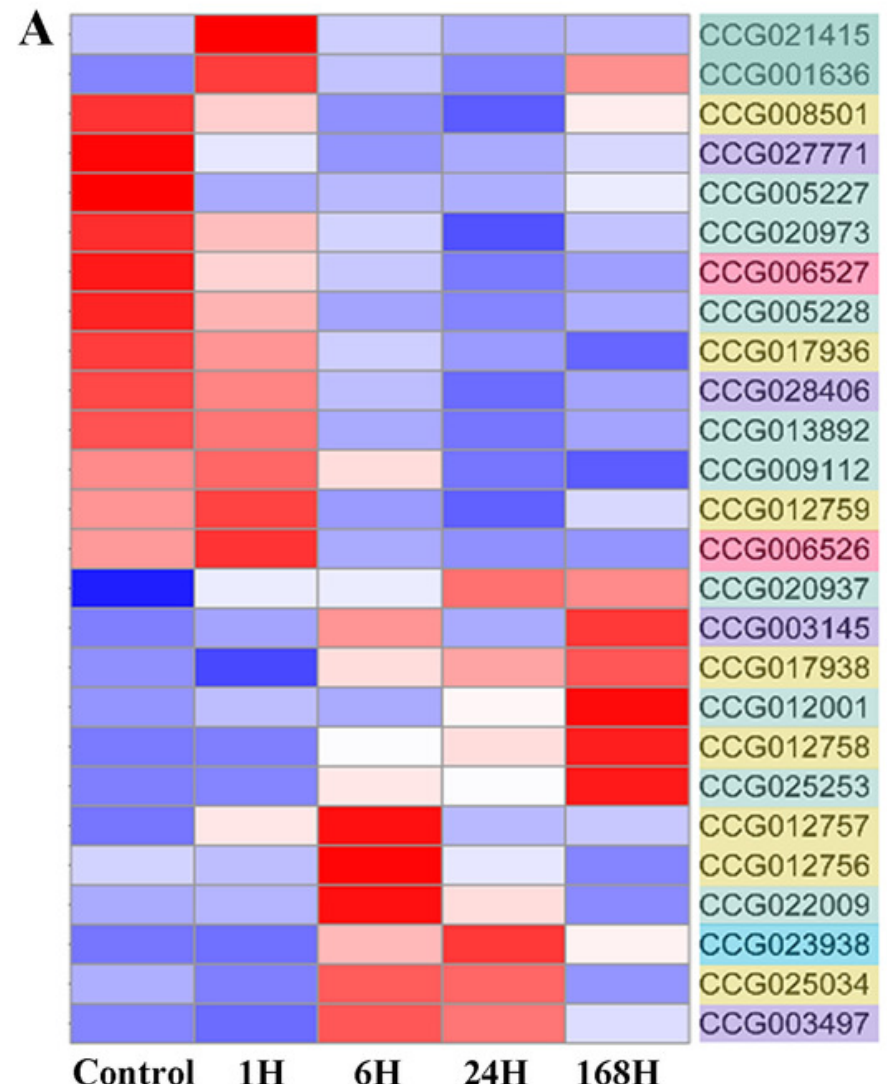

CHX

HAK NHX SOS2

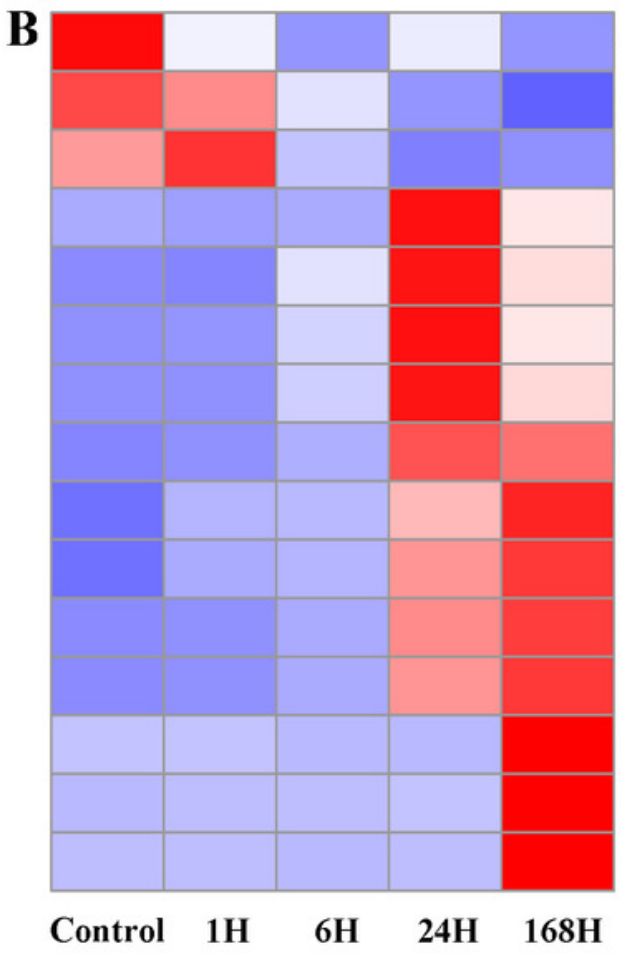

CCG003483 CCG013804 CCG016745 CCG006147 CCG015497 CCG006153 CCG008754 CCG007912 CCG015498 CCG015501 CCG010582 CCG010583 CCG014816 CCG013802 CCG014814

$\begin{array}{lllll}\text { Control } & 1 \mathrm{H} & 6 \mathrm{H} & 24 \mathrm{H} & 168 \mathrm{H}\end{array}$
1.5 1 0.5 0 $-0.5$ $-1$ $-1.5$ 


\section{Table $\mathbf{1}$ (on next page)}

Ions content changed in $C$. equisetifolia root under salt stress.

$\mathrm{Na}^{+}, \mathrm{Cl}^{-}$and $\mathrm{K}^{+}$content in root under $200 \mathrm{mM} \mathrm{NaCl}$ treatment for $0,1,6,24$, and $168 \mathrm{~h}$.

Values represent mean \pm standard deviation; $n=3$. Values within a column with different

letters indicate significant difference $(P<0.05$ using analysis of variance at $95 \%$ confidence level). 
1 Table 1 Ions content changed in $C$. equisetifolia root under salt stress. $\mathrm{Na}^{+}, \mathrm{Cl}^{-}$and $\mathrm{K}^{+}$content in root under 200

$2 \mathrm{mM} \mathrm{NaCl}$ treatment for $0,1,6,24$, and $168 \mathrm{~h}$. Values represent mean \pm standard deviation; $\mathrm{n}=3$. Values within a

3 column with different letters indicate significant difference $(\mathrm{P}<0.05$ using analysis of variance at $95 \%$ confidence

4 level).

\begin{tabular}{ccccc}
\hline Name & $\mathrm{K}^{+} / \mathrm{Na}^{+}$ & $\mathrm{K}^{+}(\mathrm{g} / \mathrm{kg})$ & $\mathrm{Na}^{+}(\mathrm{g} / \mathrm{kg})$ & $\mathrm{Cl}^{-}(\mathrm{g} / \mathrm{kg})$ \\
\hline Control & $3.123^{\mathrm{a}}$ & $15.118 \pm 1.057^{\mathrm{a}}$ & $4.841 \pm 1.257^{\mathrm{a}}$ & $8.565 \pm 1.254^{\mathrm{a}}$ \\
$\mathrm{H} 1$ & $1.149^{\mathrm{b}}$ & $14.71 \pm 0.32^{\mathrm{a}}$ & $12.798 \pm 0.132^{\mathrm{b}}$ & $15.654 \pm 1.798^{\mathrm{b}}$ \\
$\mathrm{H} 6$ & $0.782^{\mathrm{bc}}$ & $13.618 \pm 1.118^{\mathrm{a}}$ & $17.416 \pm 1.829^{\mathrm{c}}$ & $23.416 \pm 0.909^{\mathrm{c}}$ \\
$\mathrm{H} 24$ & $0.328^{\mathrm{bc}}$ & $10.14 \pm 0.657^{\mathrm{b}}$ & $30.903 \pm 1.404^{\mathrm{d}}$ & $48.237 \pm 3.208^{\mathrm{d}}$ \\
$\mathrm{H} 168$ & $0.049^{\mathrm{c}}$ & $1.634 \pm 0.161^{\mathrm{c}}$ & $33.503 \pm 1.352^{\mathrm{d}}$ & $59.903 \pm 2.024^{\mathrm{e}}$ \\
\hline
\end{tabular}

5 